\title{
Parametric Study on the Thermal Performance and Optimal Design Elements of Solar Air Heater Enhanced with Jet Impingement on a Corrugated Absorber Plate
}

\author{
Alsanossi M. Aboghrara $\left(\mathbb{D},{ }^{1,2}\right.$ M. A. Alghoul $\left(\mathbb{D},{ }^{3,4}\right.$ B. T. H. T. Baharudin $\left(\mathbb{D},{ }^{1}\right.$ A. M. Elbreki, ${ }^{5}$ \\ A. A. Ammar, ${ }^{5}$ K. Sopian $\left(1,{ }^{5}\right.$ and A. A. Hairuddin ${ }^{1}$ \\ ${ }^{1}$ Mechanical Department, Faculty of Engineering, UPM, 43400 Serdang, Selangor, Malaysia \\ ${ }^{2}$ Physics Department, Faculty of Science Traghen, University of Sebha, Sebha, Libya \\ ${ }^{3}$ Center of Research Excellence in Renewable Energy (CoRERE), King Fahd University of Petroleum and Minerals (KFUPM), \\ Dhahran 31261, Saudi Arabia \\ ${ }^{4}$ Energy and Building Research Center, Kuwait Institute for Scientific Research, Safat, 13109 Kuwait City, Kuwait \\ ${ }^{5}$ Solar Energy Research Institute, Universiti Kebangsaan Malaysia, 43600 Bangi, Selangor, Malaysia
}

Correspondence should be addressed to Alsanossi M. Aboghrara; alsanossi_15@yahoo.com, M. A. Alghoul; dr.alghoul@gmail.com, and B. T. H. T. Baharudin; hangtuah@upm.edu.my

Received 23 March 2017; Revised 21 June 2017; Accepted 11 July 2017; Published 21 February 2018

Academic Editor: Alberto Álvarez-Gallegos

Copyright (C) 2018 Alsanossi M. Aboghrara et al. This is an open access article distributed under the Creative Commons Attribution License, which permits unrestricted use, distribution, and reproduction in any medium, provided the original work is properly cited.

\begin{abstract}
Previous works revealed that cross-corrugated absorber plate design and jet impingement on a flat absorber plate resulted in a significant increase in the performance of a solar air heater (SAH). Involving these two designs into one continuous design to improve the SAH performance remains absent in the literature. This study aimed to evaluate the achieved enhancement on performance parameters of a SAH with jet impingement on a corrugated absorber plate. An energy balance model was developed to compare the performance parameters of the proposed SAH with the other two SAHs. At a clear sky day and a mass flow rate of $0.04 \mathrm{~kg} / \mathrm{s}$, the hourly results revealed that the max fluid outlet temperatures for the proposed SAH, jet-to-flat plate $\mathrm{SAH}$, and cross-corrugated plate $\mathrm{SAH}$ are 321,317 , and $313 \mathrm{~K}$, respectively; the max absorber plate temperatures are 323.5, 326.5, and $328 \mathrm{~K}$, respectively; the maximum temperature differences between the absorber plate and fluid outlet are $\sim 3,9$, and $15 \mathrm{~K}$, respectively; the max efficiencies are $65.7,64.8$, and $60 \%$, respectively. Statistical $t$-test results confirmed significant differences between the mean efficiency of the proposed SAH and SAH with jet-to-flat plate. Hence, the proposed design is considered superior in improving the performance parameters of SAH compared to other designs.
\end{abstract}

\section{Introduction}

A solar air collector is a unit that captures the solar radiation by an absorbing medium and transforms it into thermal energy to heat the inlet ambient air. Solar air collector is an important configuration of solar thermal systems and is being widely utilized in many commercial, agriculture, industrial, and process applications [1]. A lot of equipment or appliances need to possess a capacity for high heat transfer performance in order to guarantee their quality and capability $[2,3]$. Flat plate solar air heaters are commonly used in the case of low/moderate temperature. On the other hand, a solar air heater (SAH) reports low efficiencies due to the low convective heat transfer coefficient on the smooth 
absorber's surface [4-6], the air-limiting energy extraction [7] and flow rates [8,9]. Therefore, it is necessary to develop techniques that can improve both heat and mass transfer of SAH.

Research and development (R\&D) on the improvement of heat and mass transfer are extensively reported in extant literature. One reported method of improving convective heat transfer is increasing the surface area of the device by roughening the surface, which increases the turbulence within the channel $[10,11]$.

Reviews pertaining to heat transfer and thermal efficiency in SAH in the context of artificial roughness were discussed in [12]. Prasad and Mullick [4] confirmed that the heat transfer in $\mathrm{SAH}$ was improved by placing wires under the absorber plate. This increases the absorber plate's efficiency factor. The best performance of a thermohydraulic installed on top of an artificially roughened $\mathrm{SAH}$ was reported by [13, 14] relating the installation of rough transverse wire on top of the absorber, which tolerated the varied height of roughness [15], while [8] reported the heat transfer coefficient and friction factor correlations of a rib-roughened SAH duct in the context of transitional flow. Bhagoria et al. [16] combined the topside heat transfer upon an artificially roughened SAH to a fully developed turbulent flow. Karwa and Chitoshiya [17] compared the performance of multiple geometry of roughness elements in SAHs and proved that smaller diameter protrusion wires were superior in the context of flow. Kumar et al. [18] developed correlations for friction factor in multi $\mathrm{V}$-shaped roughness of SAH. The analysis done by [19] resulted in a $12.5-20 \%$ enhancement in thermal efficiency using $60^{\circ} \mathrm{V}$-down discrete rib roughness.

In the case of a corrugated absorber, Meyer et al. [20] studied the convective heat transfer in a V-trough linear SAH; while the natural convection in a channel formed by a V-shaped surface and a flat plate was studied and compared numerically and experimentally by Zhao and Li [21]. Stasiek [22] experimented on the heat transfer and fluid flow across corrugated-undulated heat exchanger surfaces, while Piao [23] experimentally investigated the natural, forced, and mixed convective heat transfers in a cross-corrugated channel of SAH. Noorshahi et al. [24] conducted a numerical study on the natural convection in a corrugated enclosure with mixed boundary conditions, while Gao [25] numerically simulated the natural convection inside the channel formed by a flat cover and a wavelike absorbing plate. El-Sebaii et al. [26] conducted both theoretical and experimental studies on a flat plate absorber and V-corrugated plate absorbers of double pass solar air heaters. Their respective thermal performances were compared, and the results are shown in Figure 1, where it can be seen that the double pass $\mathrm{V}$-corrugated plate SAH was $11-14 \%$ more efficient than the flat plate SAH.

Metwally et al. [27] analysed a corrugated duct SAH and other five conventional designs, as per Figure 2. The enhancement factor of the convective heat transfer coefficient within the corrugated duct was 4-5. It was also confirmed that the heat removal factor of the corrugated duct collector had improved by an average value of $59 \%$,

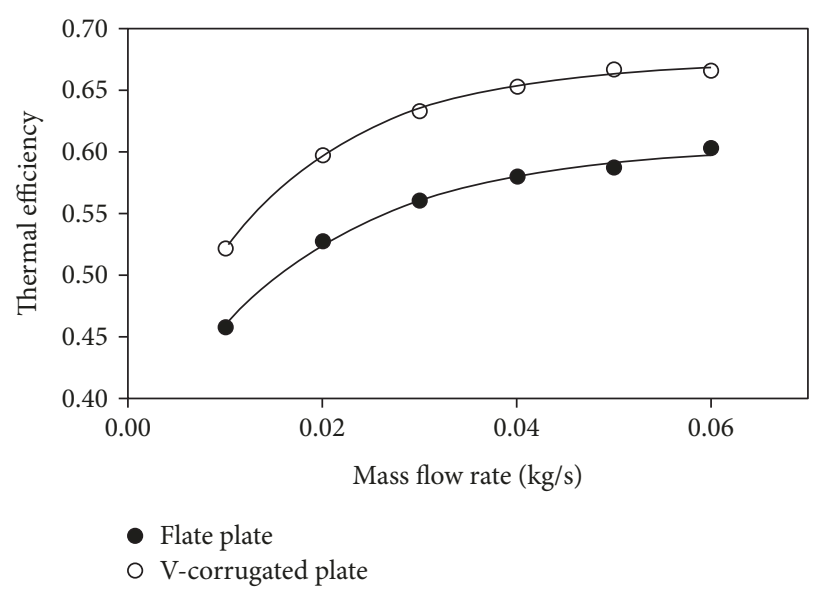

Figure 1: Effect of mass flow rate of flat and corrugated plates [26].

while its efficiency had been enhanced by $15-43 \%$ over the other conventional collectors at a flow rate range of $0.01-0.1 \mathrm{~kg} / \mathrm{sm}^{2}$ and solar insolation of $950 \mathrm{~W} / \mathrm{m}^{2}$. They concluded that the corrugated duct $\mathrm{SAH}$ can be regarded as an advanced design that is priced similar to conventional designs.

Gao et al. [2] compared the performance of three types of SAHs; two configurations were cross-corrugated, while the third was a flat plate. The thermal performance of these configurations were $58.9,60.3$, and $48.6 \%$, respectively. It can be seen that both cross-corrugated configurations exceeded that of the flat plate collector. This can be attributed to the improved turbulence and heat-transfer rates within the air flow channel on the corrugated plate, which was $~ 3.25$ more than those of the flat plate heater. It should also be pointed out that the difference in thermal performance between the two configurations of cross-corrugated $\mathrm{SAH}$ was at best quite marginal.

Liu et al. [28] analysed the effect of V-groove and cross-corrugated absorbers upon the thermal performance at multiple air mass flow rates per unit area of the collector, within $0.0025-0.5 \mathrm{~kg} / \mathrm{m}^{2} \cdot \mathrm{s}$, as per Figure 3 . It was confirmed that the cross-corrugated collector exceeded that of the $\mathrm{V}$-groove collector by $\sim 7 \%$ in terms of efficiency. This enhancement could be due to the increased turbulence within the air flow channel. The supposedly more efficient heat removal via the cross-corrugated collector as opposed to that of the $\mathrm{V}$-groove collector is detailed in Figures 3(a)-3(d).

Releasing a carefully directed fluid against a heat transfer surface could result in the efficient transfer or significant amounts of thermal energy and mass between the surface and the fluids, as per Figure 4. Therefore, jet impingement concept attracted many researchers, especially in the context of processes and thermal control applications such as turbine blades [29], microelectromechanical component [30], and solar heat absorbers [31]. The suitability of jet impingement for these aforementioned applications is mostly due to the high rates of heat transfer that takes place within the impingement region. Jet impingement results in heat transfer 


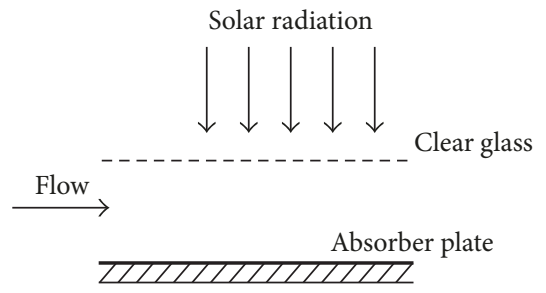

a: Flow above the absorber

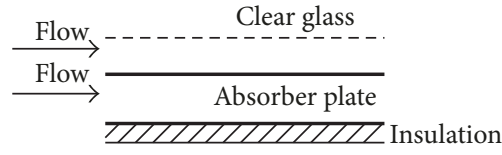

c: Flow above \& below the absorber

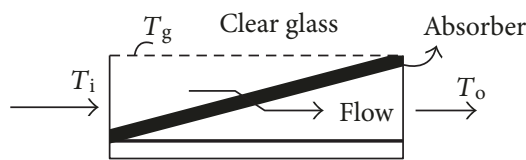

e: Flow through multilayer mesh screens

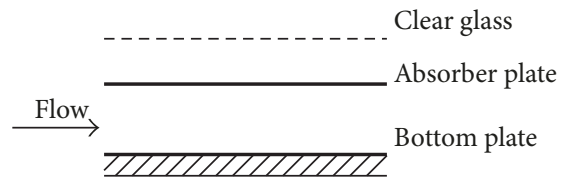

b: Flow above the absorber

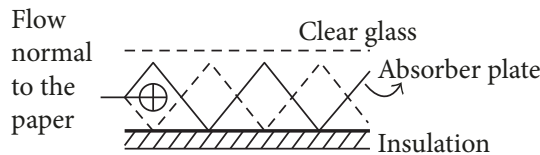

d: Flow parallel to staggered $\mathrm{V}$-folded absorber

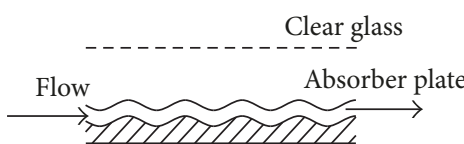

f: Flow (transversal) through corrugated duct

(a)

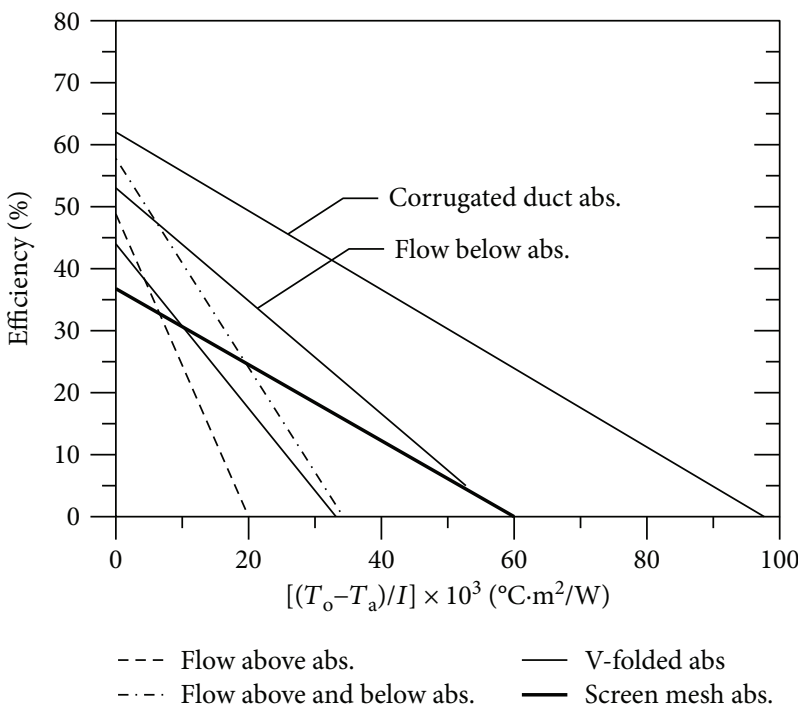

(b)

Figure 2: (a) Different solar air collector configurations [27]; (b) thermal efficiency and reduced temperature relationship for the tested collectors [27].

coefficients that are thrice to those of conventional convection cooling [32].

Sung and Mudawar [33] studied the cooling performance of microchannel flows equipped with jet impingement. Two configurations were employed, which are circular and single-slot jets, as per Figure 5. Both configurations confirmed that increased flow rates result in improved heat transfer coefficient. However, it should also be pointed out that multiple circular jets are far better at cooling compared to its single-slot jet pattern counterpart.

Belusko et al. [34] determined the thermal efficiency of the unglazed SAH installed and not installed with jet impingement under normal conditions. They reported that jet impingement resulted in significant improvement to the thermal efficiency of an unglazed SAH, as per Figure 6 . 


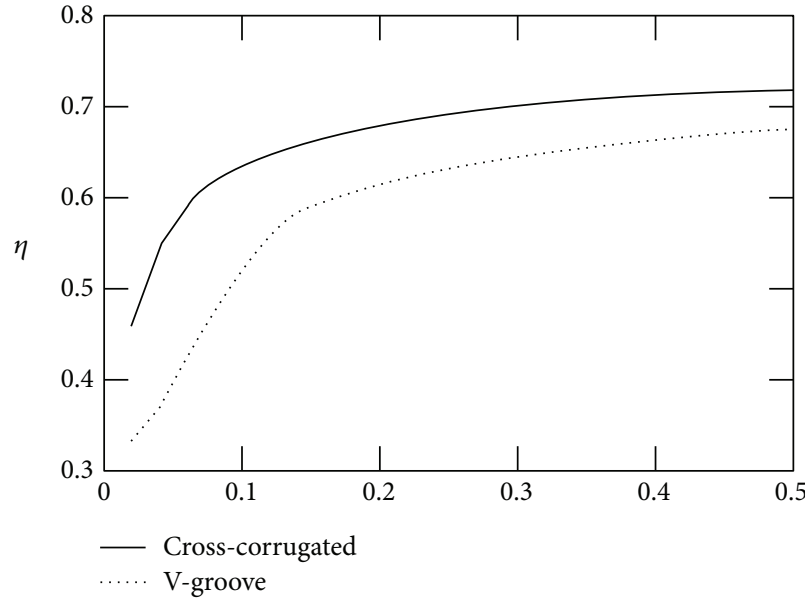

(a)

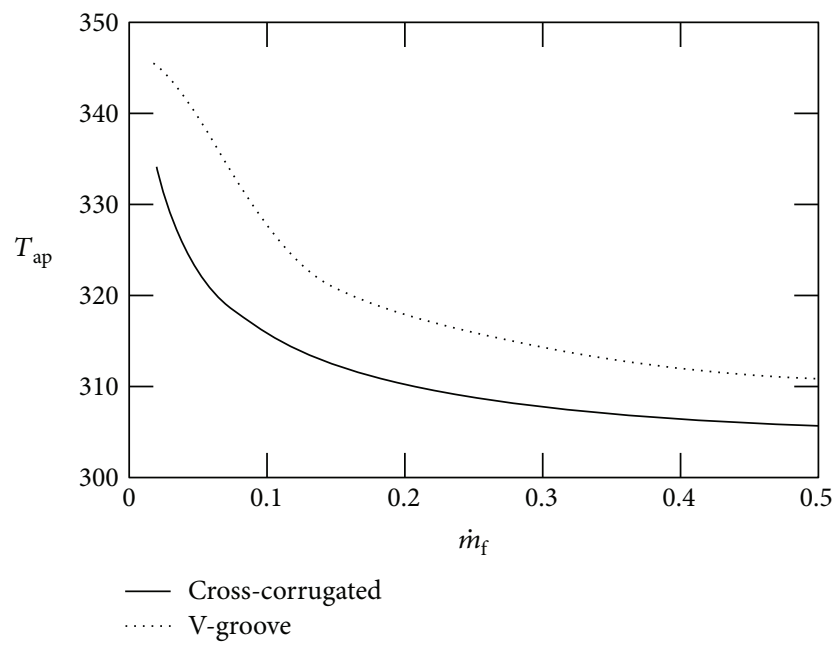

(c)

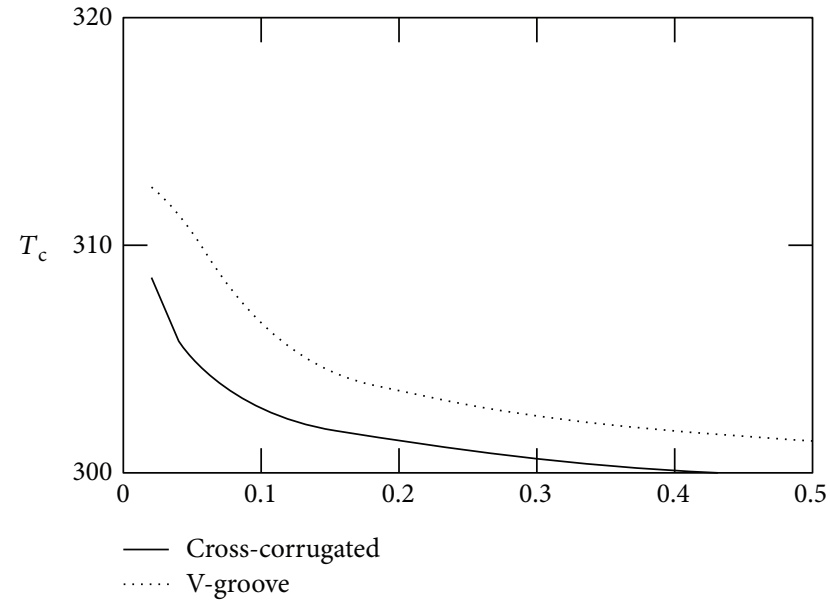

(b)

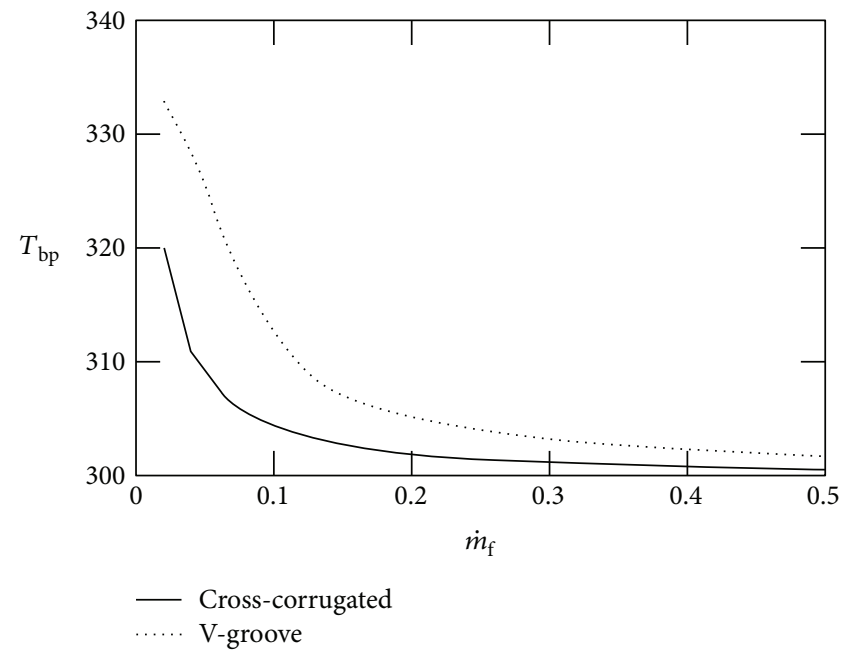

(d)

FIgURE 3: (a-d) Efficient heat removal by cross-corrugated compare to V-groove collector, Liu et al. [28].

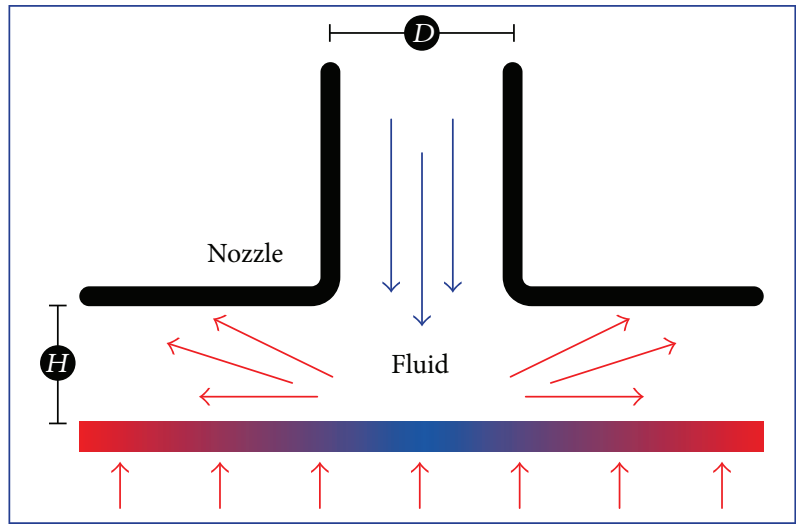

FIGURE 4: Effect of directed fluid released against the heat transferring surface.

Klein and Hetsroni [35] experimented with a wall region of the jet to improve its heat transfer using actuation against an impinging jet through a piezoelectric actuator. The setup allowed actuation at multiple amplitudes/frequencies against a steady flow of the impinging liquid jet. The chip resulted in the creation of a vortex beside the plate, and this, combined with the deflected flow, formed other vortices at both the top and bottom surfaces, which allows the deflected jet to press/divert the vortex downwards to enhance heat transfer, as per Figure 7. They reported enhancements to the heat transfer coefficients of up to $34 \%$.

Chauhan and Thakur [7] compared the thermohydraulic performance of the impinging jet solar air heater in the form of effective efficiency with that of a conventional solar air heater. They confirmed that the impinging jet solar air heater was superior to a conventional solar air heater within a specific range of Reynolds number, resulting in an enhancement of $\sim 34.54-57.89 \%$, as shown in Figure 8 .

As per the previous discussion, the corrugated absorber plate, or jet impingement, as individual approaches, significantly affected the optimization of the thermal performance of the SAH. The combination of both approaches is an avenue that has yet to be explored in literature. We proposed a modified SAH, involving the addition of a jet impingement 


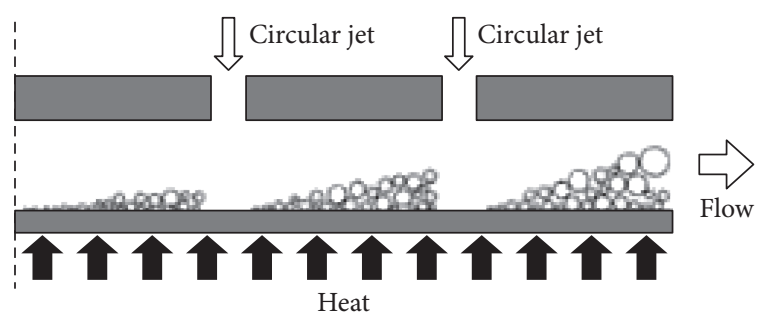

(a)

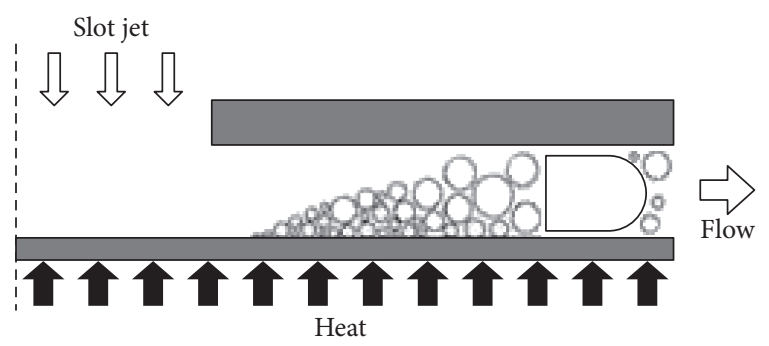

(b)

Figure 5: Two different jets. Multiple circular jets and single-slot jet [33].

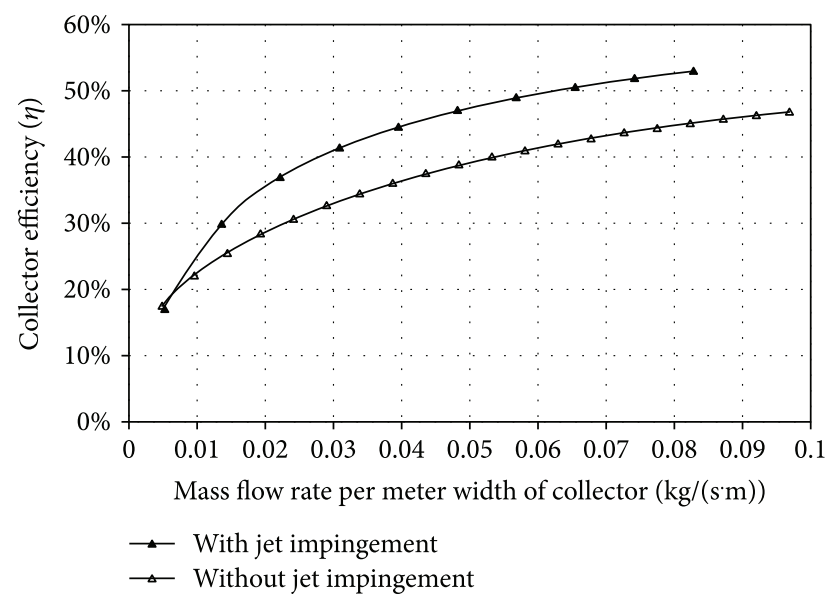

FIGURE 6: Efficiency at typical conditions of the collector with and without jet impingement [34].

on a corrugated absorber plate. The mathematical intricacies pertaining to this design will be analysed using energy balance analysis.

\section{Materials and Method}

2.1. Research Design. Figure 9 describes the steps involved in this study.

2.2. Materials. This study compares the proposed SAH design to two previous SAH designs to pinpoint the potential enhancement that can be realized in terms of temperature outlet, useful energy, and efficiency. The previous SAH designs with the cross-corrugated absorber plate [36] and the SAH design with jet impingement on a flat absorber plate [37] are illustrated in Figures 10(a) and 10(b), respectively.
While the schematic diagram of the proposed SAH design with jet impingement on the corrugated absorber plate is illustrated in Figure 11. The collector includes a frame of rectangular cross-section with an inlet and outlet for the passage of air, sheet of glass cover at the top of the frame, and an absorber plate mounted in the frame below the cover. The absorber is a corrugated plate coated with black paint on both sides and a jet plate spacing a distance below the absorber plate. Jets of air are directed through the holes of the jet plate and impinge on the lower surface of the corrugated absorber plate to increase the efficiency of the heat transfer, while the channels facilitate the corrugated flow of the spent jets for discharging via the outlet.

2.3. Mathematical Model Assumptions. This study represents a mathematical approach using the energy balance equations to compare and evaluate the performance of the three implemented designs of the solar air heater. The values will be numerically determined using the iteration approach. Figure 12 details the block diagram that is representative of the many steps taken for the calculation of the aforementioned values.

In order to model these behaviours, a number of assumptions need to be made to form the basis of the physical settings in this work. These assumptions include the following:

(1) Thermal performance of the SAH is at a steady-state condition.

(2) The sky is regarded as a black body for longwavelength radiation at an equivalent sky temperature.

(3) Front and back losses occur at ambient temperatures.

(4) The collector (dust, dirt, and shading) and thermal inertia of the collector components are regarded as negligible.

(5) The operating temperatures of the collector components and mean air temperatures in the air channels are all considered to be uniform.

(6) The temperature of the air varies only in the flow direction.

(7) Thermal losses caused by the wind and insulation are negligible.

(8) Jet plate holes are circular in shape.

(9) Temperature decrease caused by the glass cover, absorber plate, and bottom plate are negligible.

2.4. Research Activities. The research activities in this study are as follows:

(1) Critical evaluation of the $\mathrm{R} \& \mathrm{D}$ on the available designs of SAHs was performed to propose a conceptual design that could improve the turbulence and heat transfer rates to enhance the temperature outlet, useful energy, and the efficiency of the SAH. 

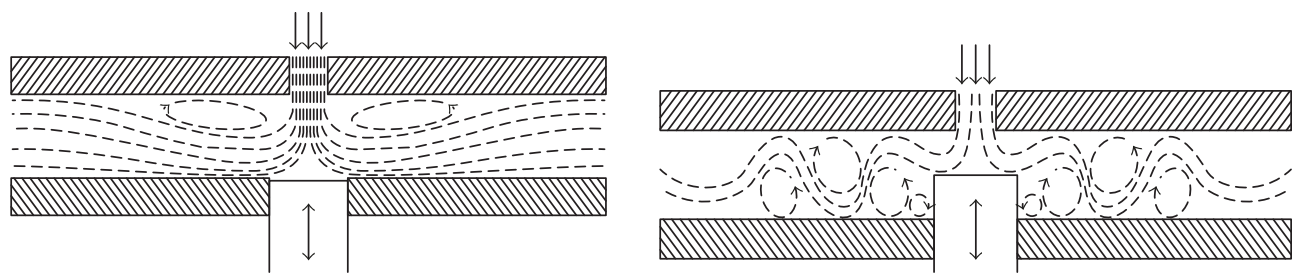

Figure 7: Characteristics of flow for a jet impinging on a flat surface and an actuating slab [35].

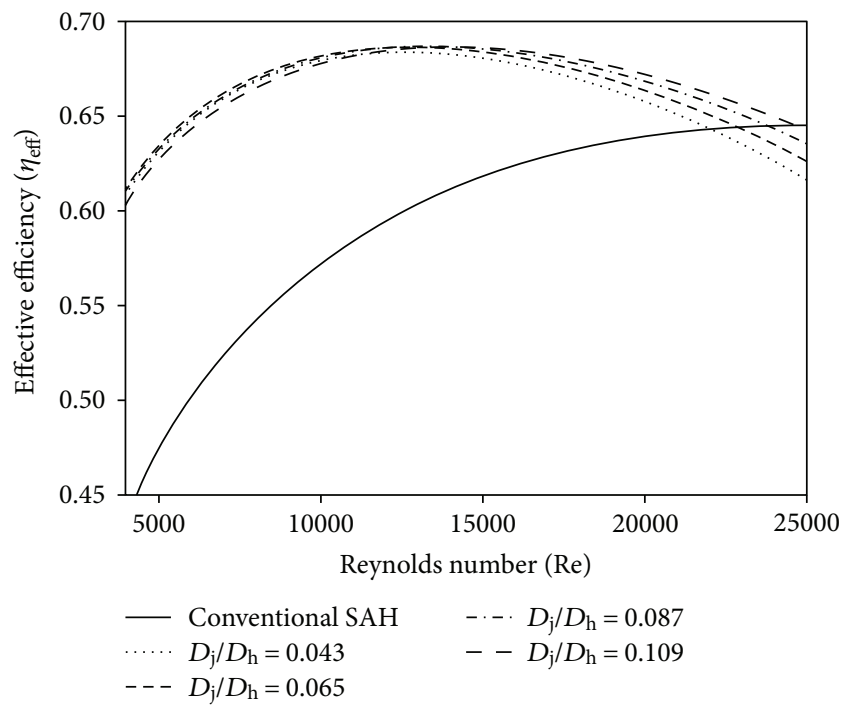

FIgURE 8: Variation of effective efficiency with Reynolds number at different values of jet diameter ratio [7].

(2) Development of a mathematical model for the proposed design of the SAH was performed.

(3) Validation of the aforementioned model (procedures and equations) versus previous designs of the $\mathrm{SAH}$ in $[36,37]$ under their reported assumptions and working conditions, as per Tables 1 and 2, respectively was performed.

(4) The thermal performance parameters of the proposed design of SAH will be compared to those of $[36,37]$ under the assumptions and working conditions outlined in Table 3.

2.5. Statistical Test Parameters. To measure the goodness of agreement between the values of the mathematical model and those reported in literature, the following statistical test parameter was used:

(1) EFF, which was reported to be the most accurate measure of closeness between predicted and referenced values [38]

$$
\mathrm{EEF}=1-\frac{\text { mean square error }(\mathrm{MSE})}{\text { variance of reference data }}
$$

EFF values that are 0 - 1 signify a close match between the predicted and reported values, while a negative EFF value means the exact opposite. Values that are as close as possible to unity is generally preferred, as these values imply a near perfect model.

A statistical paired $t$-test is used to pinpoint the differences in the mean values of the efficiency of the SAH pre- and postmodifications:

(2) Paired difference $t$-test

This test will determine whether the efficiency of the proposed SAH (jet impingement on a corrugated absorber plate) has significantly improved compared to the premodified SAH (jet impingement on a flat absorber plate). There are two probable results of this test, which is reliant upon the $p$ value; a $p$ value that is lower than the reference probability implies a statistical significance and the lack of a null hypothesis, while a $p$ value that exceeds the reference probability implies an insignificant result. In the case of this work, the reference probability was assumed to be 0.05 . The paired $t$-statistic was mathematically determined and subsequently converted to obtain the $p$ value using the $t$-table or other viable utility programs. The test statistic for the paired difference $t$-test can be calculated using [39]

$$
t=\frac{\bar{X}-\mu_{0}}{s / \sqrt{n}},
$$

where $\bar{X}$ is the average difference, $s$ is the standard deviation of the difference, and $n$ is the sample size. In paired testing, the null hypothesis is assumed when $\mu_{0}$ is 0 , which implies the lack of differences between the groups.

\section{Mathematical Model of the Proposed Design}

This section details the study of two adopted mathematical models. The first utilized the energy balance equations to compare the proposed SAH (jet impingement on a corrugated plate) with reference SAH (jet impingement on a flat plate), while the second utilized the Hottel method to apply parametric analysis and determine the optimum parameters of the proposed SAH.

3.1. Mathematical Model to Examine the Potential of the Proposed Design of SAH. The thermal network for the 


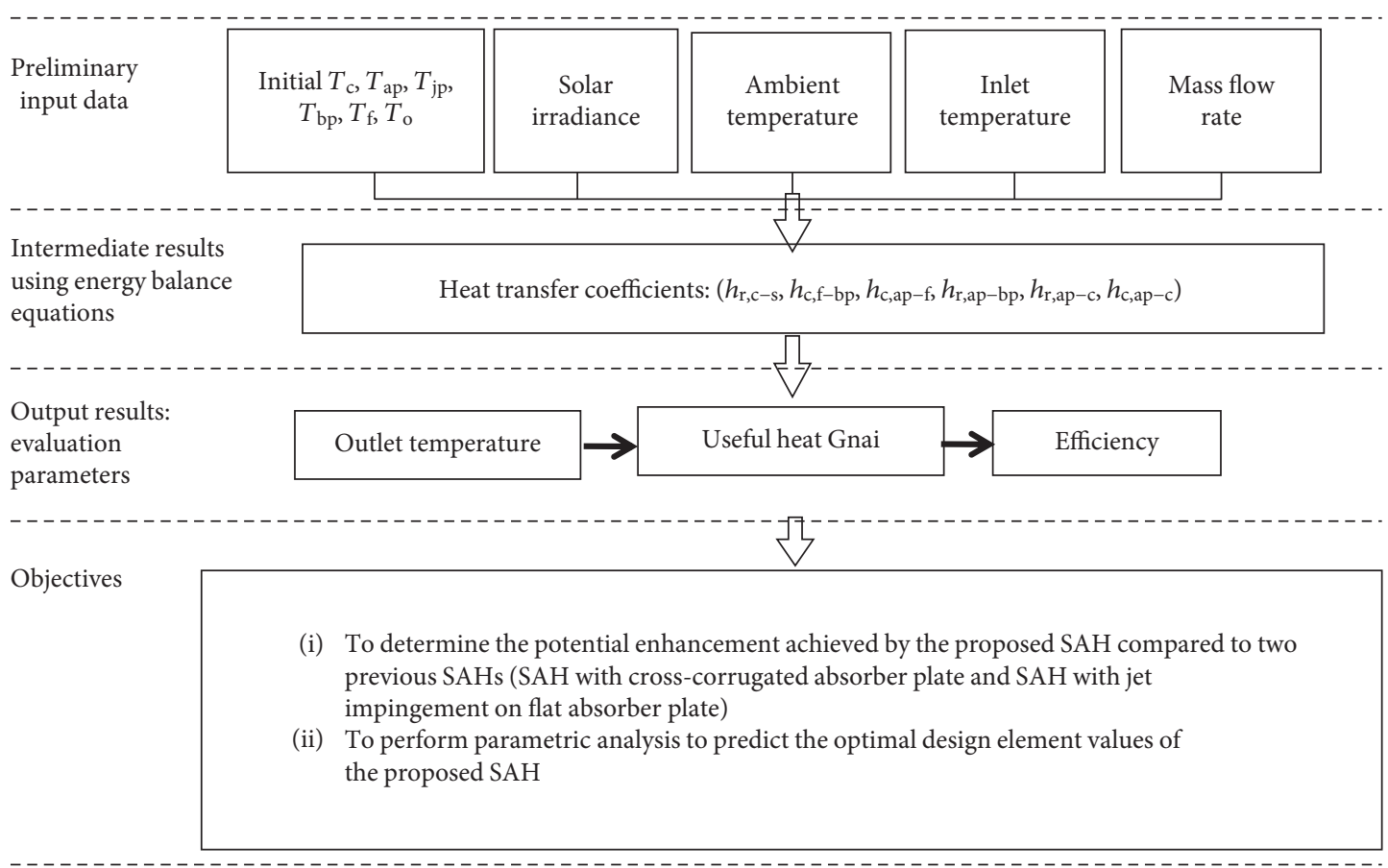

FIGURE 9: Block diagram of the research design.

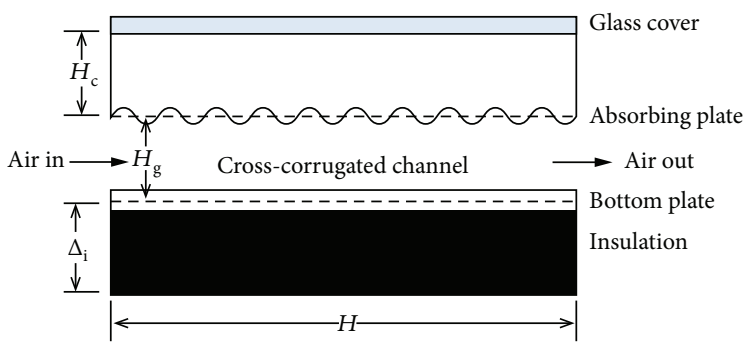

(a)

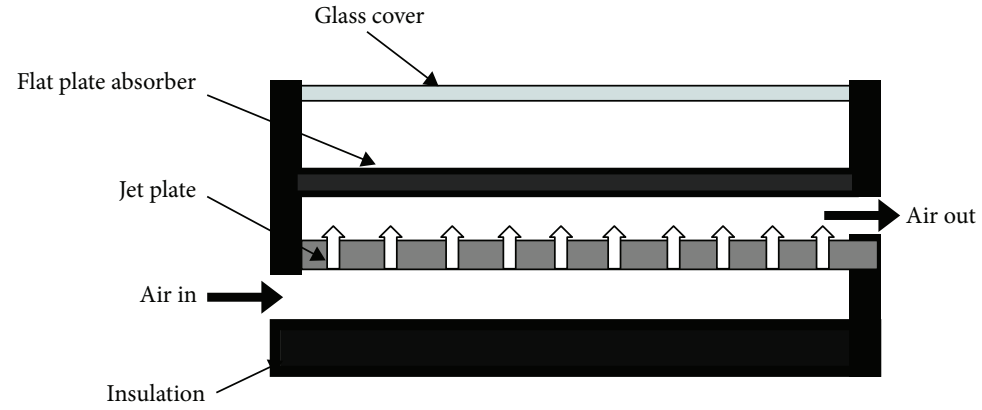

(b)

FIGURE 10: Schematic diagram of previous SAH designs (a) with a cross-corrugated absorber plate, Lin et al. [36] (b) with jet impingement on a flat absorber plate, Choudhury and Garg [37].

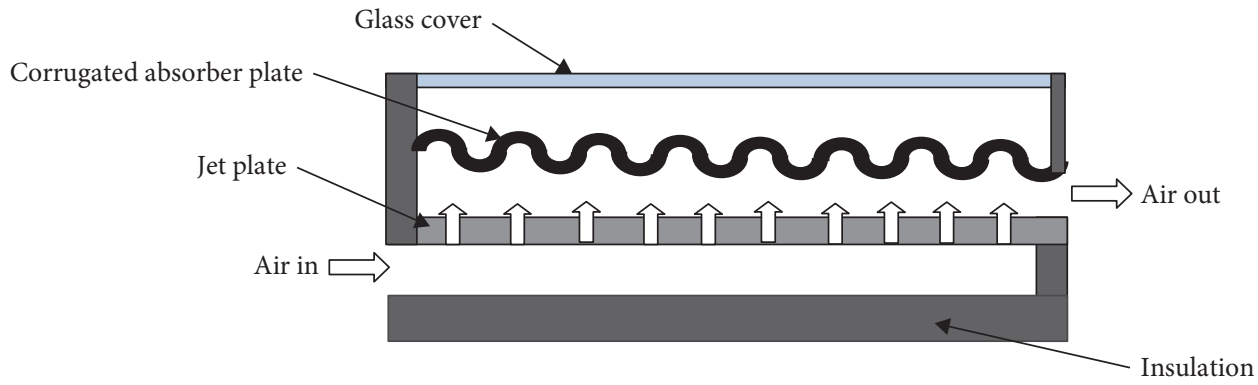

FIGURE 11: Schematic diagram of the proposed design of SAH with jet impingement on a corrugated absorber plate. 


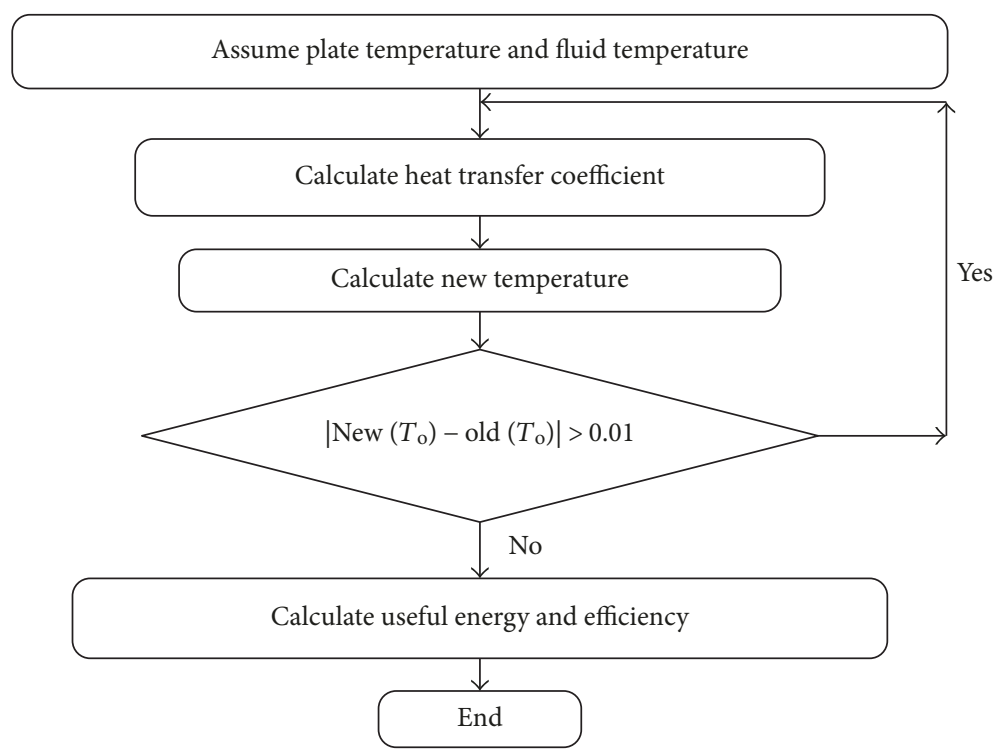

FIgURE 12: Block diagram of the calculation steps.

TABLE 1: The assumptions and working conditions of the SAH with a cross-corrugated absorber plate in [36].

\begin{tabular}{lc}
\hline Working conditions and assumptions & Value \\
\hline Solar radiation $(I)$ & $800\left(\mathrm{~W} / \mathrm{m}^{2}\right)$ \\
Ambient temperature $\left(T_{\mathrm{A}}\right)$ & $285(\mathrm{~K})$ \\
$\begin{array}{l}\text { Inlet temperature }\left(T_{\mathrm{i}}\right) \\
\text { Air mass flow rate per unit area } \\
\text { of the heater }\left(m_{\mathrm{f}}\right)\end{array}$ & $295(\mathrm{~K})$ \\
$\begin{array}{l}\text { Width of the heater }(W) \\
\text { Length of the heater }(L)\end{array}$ & $1\left(\mathrm{~kg} / \mathrm{m}^{2} \cdot \mathrm{s}\right)$ \\
$\begin{array}{l}\text { Mean gap between the absorber plate } \\
\text { and jet plate }\left(H_{\mathrm{g}}\right)\end{array}$ & $2(\mathrm{~m})$ \\
$\begin{array}{l}\text { Mean gap between the absorber plate } \\
\text { and cover }\left(H_{\mathrm{c}}\right)\end{array}$ & $0.04(\mathrm{~m})$ \\
$\begin{array}{l}\text { Convection heat transfer from the } \\
\text { glass cover due to wind }\left(h_{\mathrm{w}}\right)\end{array}$ & $0.04(\mathrm{~m})$ \\
$\begin{array}{l}\text { Thickness insulation }(b) \\
\text { Absorptivity of solar radiation of } \\
\text { the absorbing plate }\left(\alpha_{\mathrm{ap}}\right)\end{array}$ & $0.05(\mathrm{~m})$ \\
$\begin{array}{l}\text { Transmissivity of solar radiation of } \\
\text { the glass cover }(\tau \mathrm{c})\end{array}$ & 0.95 \\
$\begin{array}{l}\text { Solar radiation absorptivity of the } \\
\text { glass cover }\left(\alpha_{\mathrm{c}}\right)\end{array}$ & $\left.0.9 \mathrm{~m}^{2} \mathrm{~K}\right)$ \\
$\begin{array}{l}\text { Emissivity of thermal radiation } \\
\text { of the absorbing plate }\left(\varepsilon_{\text {ap }}\right)\end{array}$ & 0.84 \\
$\begin{array}{l}\text { Emissivity of thermal radiation of } \\
\text { the bottom plate }\left(\varepsilon_{\mathrm{bp}}\right)\end{array}$ & 0.94 \\
$\begin{array}{l}\text { Thermal radiation emissivity of the } \\
\text { glass cover }\left(\varepsilon_{\mathrm{c}}\right)\end{array}$ & 0.94 \\
Angle of inclination of the heater $(\theta)$ & 0.94 \\
\hline
\end{tabular}

components of SAH with jet impingement on a corrugated plate is illustrated in Figure 13.

The solar radiation that is captured by the absorbing plate per unit area $S\left(\mathrm{~W} / \mathrm{m}^{2}\right)$ is equivalent to the difference between
TABLE 2: The assumptions and working conditions of jet impingement on a flat absorber plate in [37].

\begin{tabular}{lc}
\hline Working conditions and assumptions & Value \\
\hline Solar radiation $(I)$ & $900\left(\mathrm{~W} / \mathrm{m}^{2}\right)$ \\
$\begin{array}{l}\text { Ambient temperature }\left(T_{\mathrm{A}}\right) \\
\text { Convection heat transfer from the } \\
\text { glass cover due to wind }\left(h_{\mathrm{w}}\right)\end{array}$ & $300(\mathrm{~K})$ \\
$\begin{array}{l}\text { Width of the heater }(W) \\
\text { Length of heater }(L)\end{array}$ & $1\left(\mathrm{~W} / \mathrm{m}^{2} \mathrm{~K}\right)$ \\
$\begin{array}{l}\text { Mean gap between the absorber } \\
\text { plate and jet plate }\left(H_{\mathrm{g}}\right)\end{array}$ & $2(\mathrm{~m})$ \\
$\begin{array}{l}\text { Mean gap between the absorber } \\
\text { plate and cover }\left(H_{\mathrm{c}}\right)\end{array}$ & $0.05(\mathrm{~m})$ \\
$\begin{array}{l}\text { Absorptivity of solar radiation of } \\
\text { the absorbing plate }\left(\alpha_{\mathrm{ap}}\right)\end{array}$ & $0.05(\mathrm{~m})$ \\
$\begin{array}{l}\text { Transmissivity of solar radiation of } \\
\text { the glass cover }\left(\tau_{\mathrm{c}}\right)\end{array}$ & 0.95 \\
$\begin{array}{l}\text { Spacing between absorber and } \\
\text { back plate }(z)\end{array}$ & 0.90 \\
$\begin{array}{l}\text { Diameter of the hole or nozzle } \\
\text { Center to center spacing between } \\
\text { holes/nozzles }\end{array}$ & $0.1(\mathrm{~m})$ \\
\hline
\end{tabular}

the incident solar radiation and the optical loss and can be mathematically determined as in [2].

$$
S \simeq 0.96 \tau_{\mathrm{c}} \alpha_{\mathrm{ap}} I
$$

In steady state conditions, the energy balance equations for the cover, absorber, jet plate, back plate, air in the passage between the back plate and jet plate, and air in the passage between the absorber and back plates in the case of the jet plate air heater are as follows: 
TABLE 3: Working conditions and assumptions used in evaluating the potential of the proposed design.

\begin{tabular}{lc}
\hline Parameter & Value \\
\hline Solar radiation $(I)$ & $\begin{array}{c}\text { Clear sky day }\left(\mathrm{W} / \mathrm{m}^{2}\right) \\
\text { Associated ambient } \\
\text { temperature of the selected } \\
\text { clear sky day, 303-317.5 K }\end{array}$ \\
$\begin{array}{lc}\text { Ambient temperature }\left(T_{\mathrm{A}}\right) & 0.02-0.08(\mathrm{~kg} / \mathrm{s})\end{array}$ \\
$\begin{array}{l}\text { Air mass flow rate per unit area } \\
\text { of the solar air heater }\left(m_{\mathrm{f}}\right)\end{array}$ & $0.3(\mathrm{~m})$ \\
$\begin{array}{l}\text { Width of the heater }(\mathrm{W}) \\
\text { Length of the heater }(L)\end{array}$ & $1.4(\mathrm{~m})$ \\
$\begin{array}{l}\text { Mean gap between the absorber } \\
\text { plate and jet plate }\left(H_{\mathrm{g}}\right)\end{array}$ & $0.04(\mathrm{~m})$ \\
$\begin{array}{l}\text { Mean gap between the absorber } \\
\text { plate and cover }\left(H_{\mathrm{c}}\right)\end{array}$ & $0.04(\mathrm{~m})$ \\
$\begin{array}{l}\text { Convection heat transfer from } \\
\text { the glass cover due to wind }\left(h_{\mathrm{w}}\right)\end{array}$ & $11.4\left(\mathrm{~W} / \mathrm{m}^{2} \mathrm{~K}\right)$ \\
$\begin{array}{l}\text { Absorptivity of solar radiation } \\
\text { of the absorbing plate }\left(\alpha_{\mathrm{ap}}\right)\end{array}$ & 0.95 \\
$\begin{array}{l}\text { Transmissivity of solar radiation of } \\
\text { the glass cover }(\tau \mathrm{c})\end{array}$ & 0.84 \\
$\begin{array}{l}\text { Solar radiation absorptivity of } \\
\text { the glass cover }\left(\alpha_{\mathrm{c}}\right)\end{array}$ & 0.96 \\
$\begin{array}{l}\text { Emissivity of thermal radiation of } \\
\text { the absorbing plate }\left(\varepsilon_{\mathrm{ap}}\right)\end{array}$ & 0.94 \\
$\begin{array}{l}\text { Emissivity of thermal radiation of } \\
\text { the bottom plate }\left(\varepsilon_{\mathrm{bp}}\right)\end{array}$ & 0.94 \\
$\begin{array}{l}\text { Thermal radiation emissivity of } \\
\text { the glass cover }\left(\varepsilon_{\mathrm{c}}\right)\end{array}$ & \\
\hline
\end{tabular}

(i) On the glass cover

The energy balance equation for the glass cover is as follows:

$$
\begin{aligned}
\alpha_{\mathrm{c}} I+\left(h_{\mathrm{c}, \mathrm{ap}-\mathrm{c}}+h_{\mathrm{r}, \mathrm{ap}-\mathrm{c}}\right)\left(T_{\mathrm{ap}}-T_{\mathrm{c}}\right)= & \left(h_{\mathrm{w}}+h_{\mathrm{r}, \mathrm{c}-\mathrm{s}}\right) \\
& \cdot\left(T_{\mathrm{c}}-T_{\mathrm{a}}\right),
\end{aligned}
$$

where the absorptivity of solar radiation by the glass cover is $\alpha_{c}$, while the energy gain is $\alpha_{c} I$.

(ii) On the absorbing plate

The energy balance for the absorbing plate is described as follows:

$$
\begin{aligned}
S \frac{A_{\mathrm{h}}}{A_{\mathrm{a}}}= & \left(h_{\mathrm{c}, \mathrm{ap}-\mathrm{c}}+h_{\mathrm{r}, \mathrm{ap}-\mathrm{c}}\right)\left(T_{\mathrm{ap}}-T_{\mathrm{c}}\right) \\
& +h_{\mathrm{r}, \mathrm{ap}-\mathrm{j}}\left(T_{\mathrm{ap}}-T_{\mathrm{j}}\right)+h_{\mathrm{c}, \mathrm{ap}-\mathrm{a} 2}\left(T_{\mathrm{ap}}-T_{\mathrm{o} 1}\right),
\end{aligned}
$$

where $S$ represents the absorbed solar radiation by the absorber metal and $h_{c, \text { ap }-\mathrm{c}}$ and $h_{\mathrm{r}, \mathrm{ap}-\mathrm{c}}$ represent convection and radiation heat transfer coefficients between the absorber plate and glass cover,

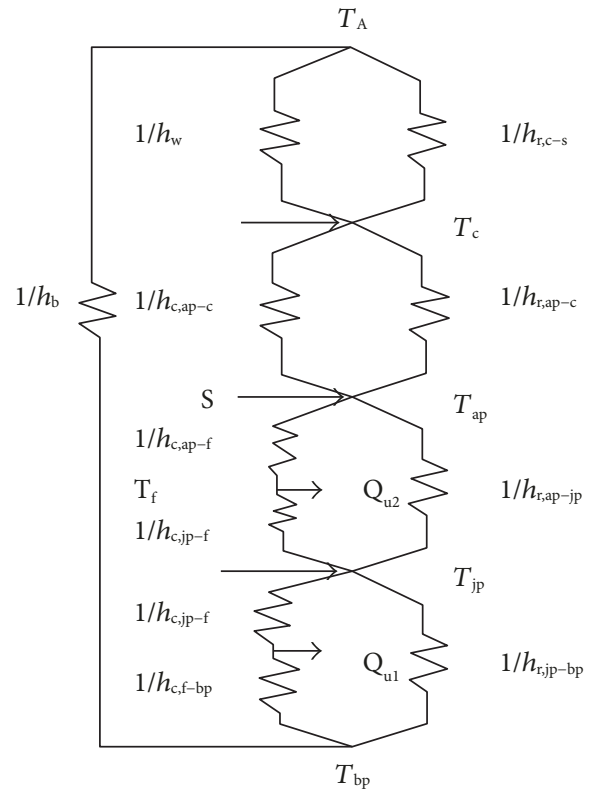

Figure 13: Thermal network for the single-cover solar air heater.

respectively, $h_{\mathrm{r}, \mathrm{ap}-\mathrm{j}}$, represents radiation heat transfer coefficient between the absorbing and jet plates, and $h_{c, \text { ap-a2 }}$ represents convection heat transfer coefficient of the fluid on the absorbing plate.

(iii) For the fluid, energy balance equations are obtained from [37].

(a) The fluid between the bottom plate and jet plate is as follows:

$$
\begin{aligned}
C_{\mathrm{p}} \dot{m}_{1}\left(T_{\mathrm{o} 1}-T_{\mathrm{A}}\right)= & h_{\mathrm{c}, \mathrm{j}-\mathrm{a} 1}\left(T_{\mathrm{j}}-T_{\mathrm{a}}\right) \\
& +h_{\mathrm{c}, b-\mathrm{a} 1}\left(T_{\mathrm{b}}-T_{\mathrm{a}}\right) .
\end{aligned}
$$

(b) The fluid between the absorber and jet plates is as follows:

$$
\begin{aligned}
C_{\mathrm{p}} \dot{m}_{1}\left(T_{\mathrm{o}}-T_{\mathrm{o} 1}\right)= & h_{\mathrm{c}, \mathrm{j}-\mathrm{a} 2}\left(T_{\mathrm{j}}-T_{\mathrm{o} 1}\right) A_{\mathrm{h}} \\
& +h_{\mathrm{c}, \mathrm{ap}-\mathrm{a} 2}\left(T_{\mathrm{ap}}-T_{\mathrm{o} 1}\right)\left(A_{\mathrm{a}}\right) .
\end{aligned}
$$

(iv) On the jet plate, the energy balance equation is as follows:

$$
\begin{aligned}
h_{\mathrm{r}, \mathrm{ap}-\mathrm{j}}\left(T_{\mathrm{ap}}-T_{\mathrm{j}}\right)\left(\frac{A_{\mathrm{a}}}{A_{\mathrm{h}}}\right)= & h_{\mathrm{c}, \mathrm{j}-\mathrm{a} 2}\left(T_{\mathrm{j}}-T_{\mathrm{o} 1}\right) \\
& +h_{\mathrm{c}, \mathrm{j}-\mathrm{a} 1}\left(T_{\mathrm{j}}-T_{\mathrm{a}}\right) \\
& +h_{\mathrm{r}, \mathrm{j}-\mathrm{bp}}\left(T_{\mathrm{j}}-T_{\mathrm{bp}}\right) .
\end{aligned}
$$

In the case of the bottom plate, heat gains via fluids through convection are represented by $h_{c, b p-a l}$ and the jet plate via thermal radiation is represented by $h_{\mathrm{r}, \mathrm{j}-\mathrm{bp}}$, both of which are offsetted by the thermal loss to the surroundings via conduction, represented by $h_{\mathrm{b}}\left(\mathrm{W} / \mathrm{m}^{2} \mathrm{~K}\right)$, 

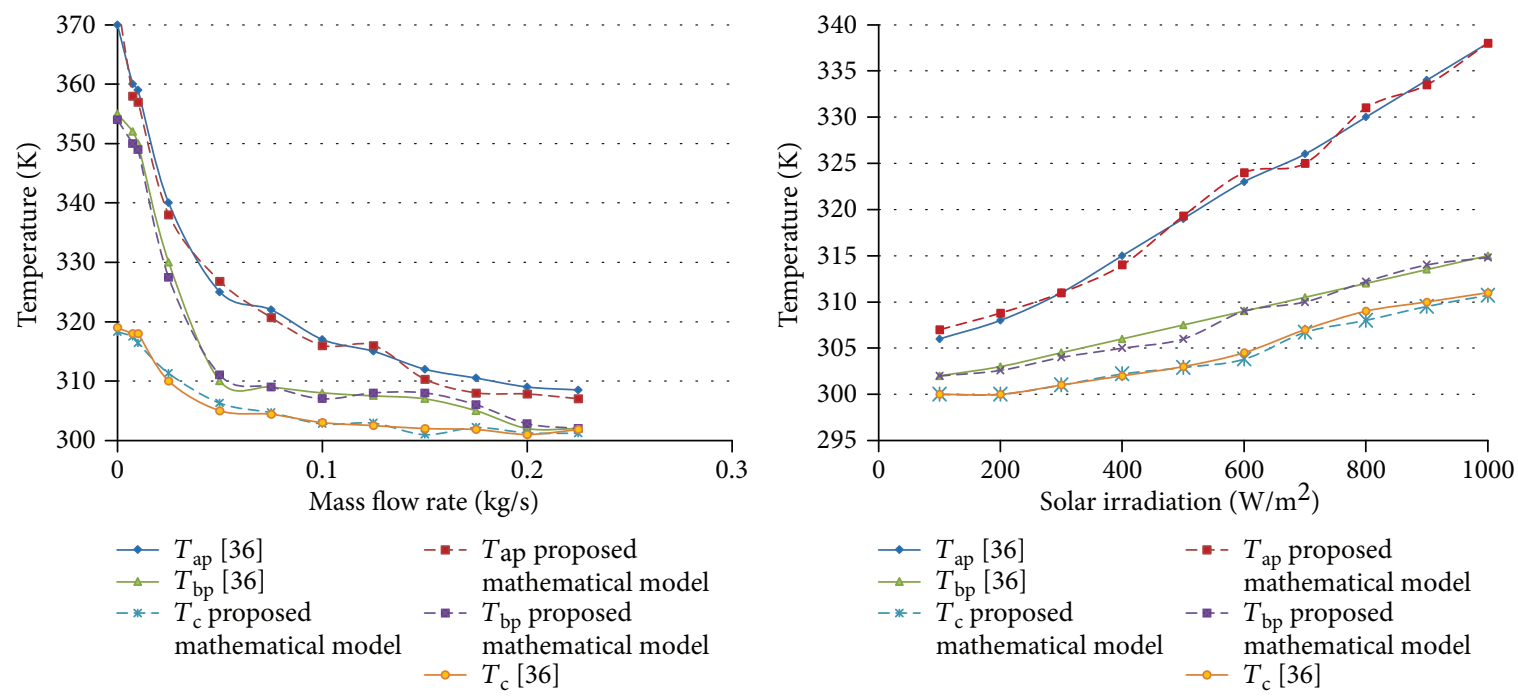

(a)
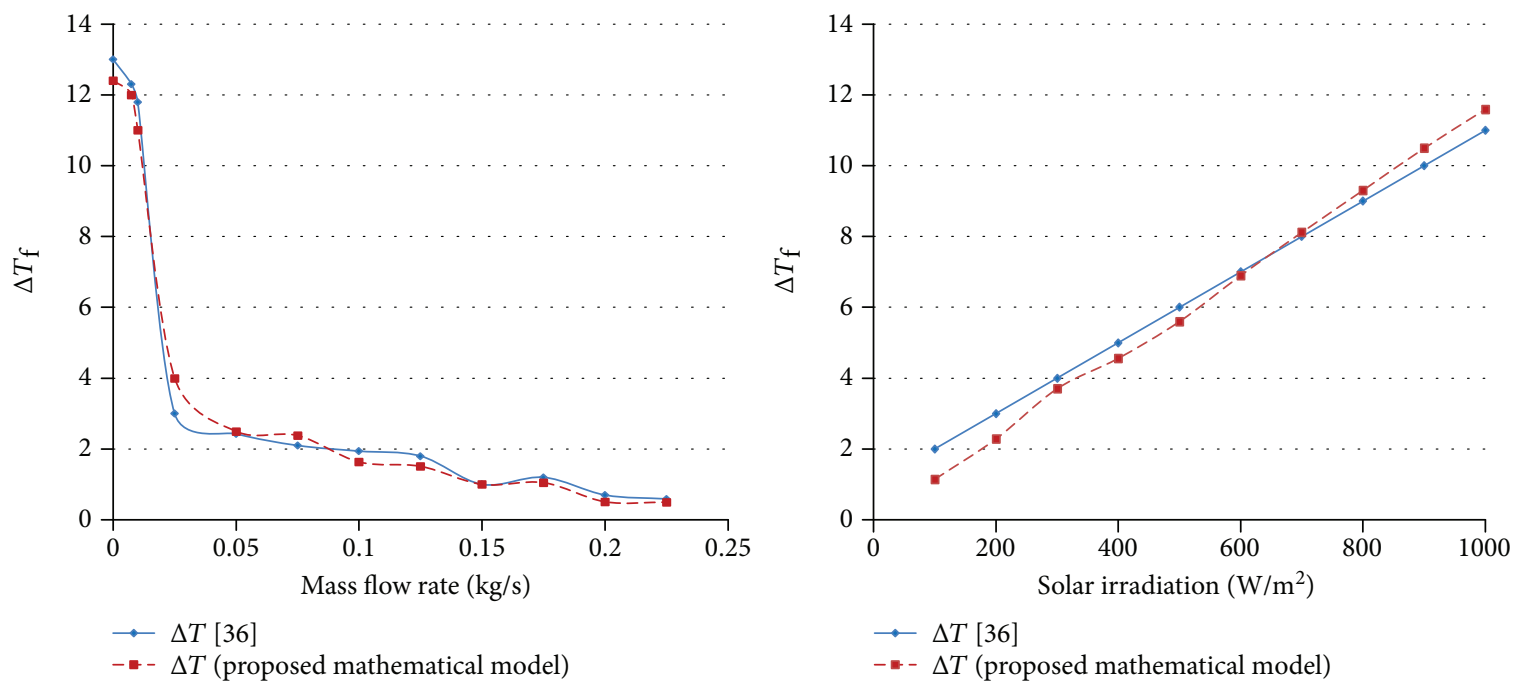

(b)
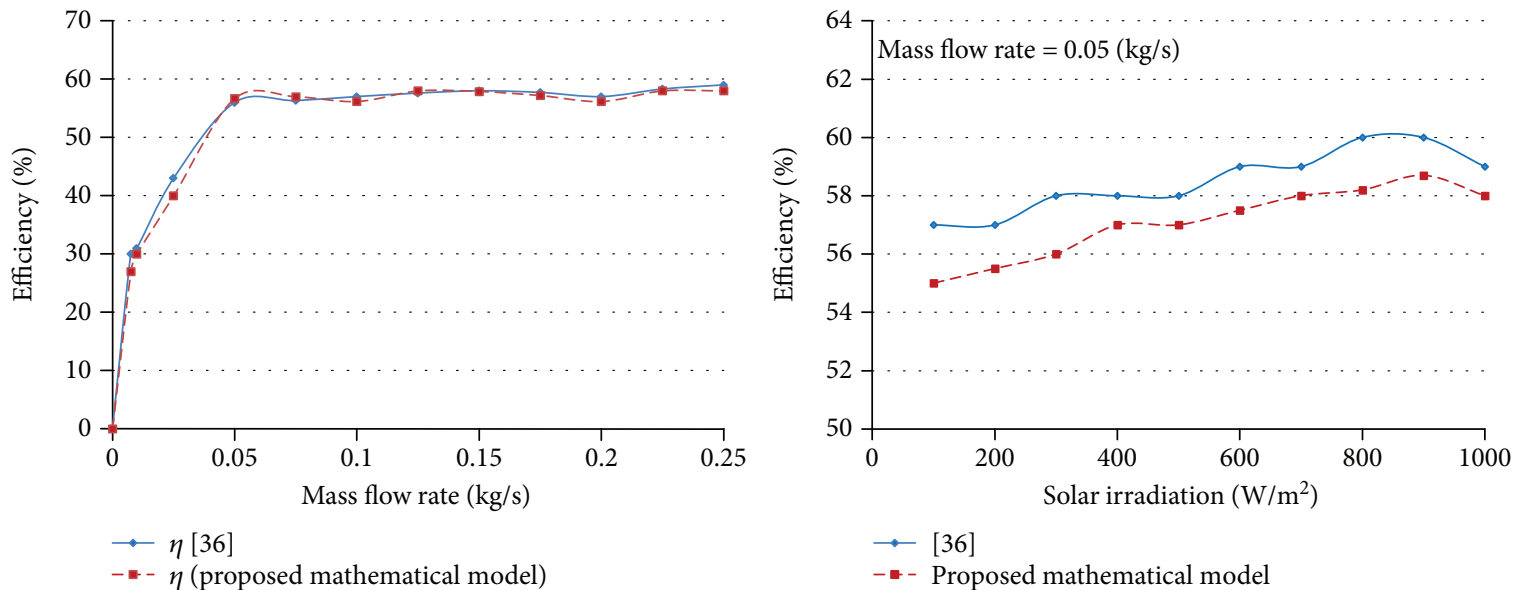

(c)

FIGURE 14: Comparison of solar air heater performance parameters obtained from the proposed mathematical model and that in [36]. (a) Predicted temperature of absorber plate, bottom plate, and glass cover plate of SAH versus mass flow rate and solar irradiation. (b) Predicted fluid temperature difference versus mass flow rate and solar irradiation. (c) Predicted SAH efficiency versus mass flow rate and solar irradiation. 


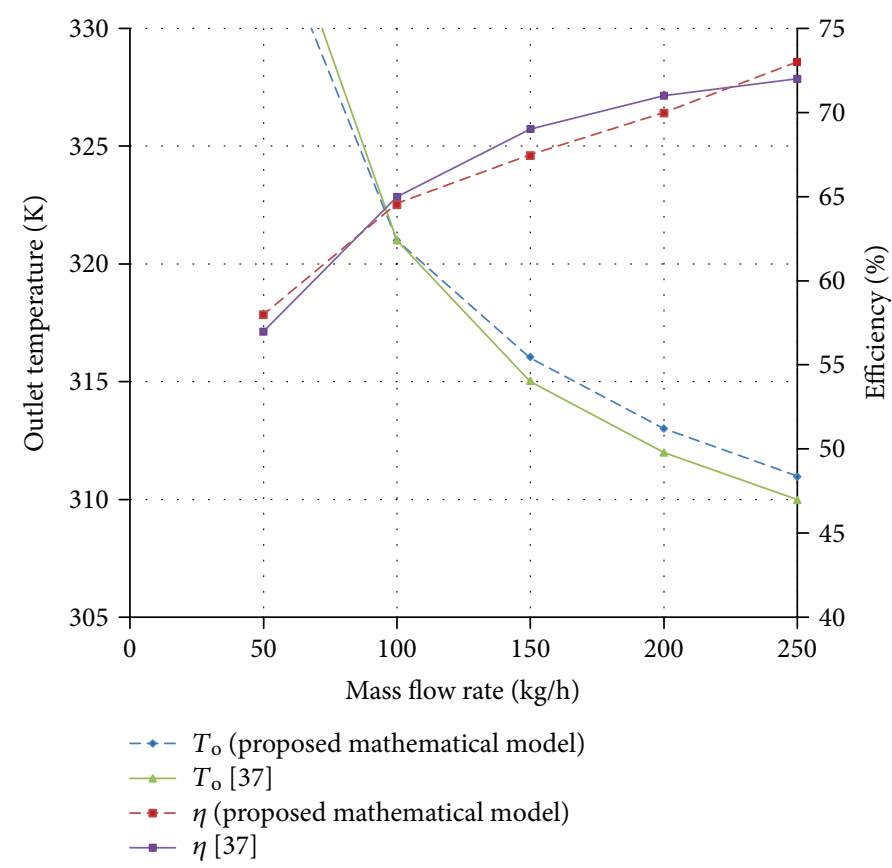

FIGURE 15: Predicted outlet temperature and efficiency of the SAH obtained from the proposed mathematical model and from reference work [37].

TABLE 4: Accuracy of the proposed mathematical model in predicting the values of different SAH evaluation parameters for the two reference works.

\begin{tabular}{|c|c|c|c|}
\hline Reference & Parameters of SAH & $\begin{array}{l}\text { Statistical EFF test result } \\
\text { "evaluation of parameters } \\
\text { versus mass flow rate" }\end{array}$ & $\begin{array}{c}\text { Statistical EFF test result } \\
\text { "evaluation of parameters } \\
\text { versus solar radiation" }\end{array}$ \\
\hline \multirow{5}{*}{ Lin et al. [36] } & Glass cover temperature values $\left(T_{\mathrm{c}}\right)$ & 0.98 & 0.9642 \\
\hline & Absorber plate temperature values $\left(T_{\mathrm{ap}}\right)$ & 0.99 & 0.9546 \\
\hline & Bottom plate temperature $\left(T_{\mathrm{bp}}\right)$ & 0.97 & 0.9554 \\
\hline & Fluid temperature difference $\left(\Delta T=T_{\mathrm{o}}-T_{\mathrm{i}}\right)$ & 0.97 & 0.9569 \\
\hline & Collector efficiency & 0.27 & 0.2105 \\
\hline \multirow{2}{*}{ Choudhury and Garg [37] } & Outlet temperature values $\left(T_{\mathrm{o}}\right)$ & 0.98 & - \\
\hline & Collector efficiency & 0.97 & - \\
\hline
\end{tabular}

which is the conduction heat transfer coefficient across the insulation, where

$$
h_{\mathrm{r}, \mathrm{j}-\mathrm{bp}}\left(T_{\mathrm{j}}-T_{\mathrm{bp}}\right)=h_{\mathrm{c}, \mathrm{bp}-\mathrm{a} 1}\left(T_{\mathrm{bp}}-T_{\mathrm{a}}\right)+h_{\mathrm{b}}\left(T_{\mathrm{bp}}-T_{\mathrm{A}}\right) \text {, }
$$

where $T_{\mathrm{a}}$ is $T_{\mathrm{a}}=\left(T_{\mathrm{A}}+T_{\mathrm{O} 1}\right) / 2$

It is found from (4) that

$$
T_{\mathrm{c}}=\frac{\alpha_{\mathrm{c}} I+\left(h_{\mathrm{c}, \mathrm{ap}-\mathrm{c}}+h_{\mathrm{r}, \mathrm{ap}-\mathrm{c}}\right)\left(T_{\mathrm{ap}}\right)+\left(h_{\mathrm{w}}+h_{\mathrm{r}, \mathrm{c}-\mathrm{s}}\right)\left(T_{\mathrm{a}}\right)}{\left(h_{\mathrm{c}, \mathrm{ap}-\mathrm{c}}+h_{\mathrm{r}, \mathrm{ap}-\mathrm{c}}+h_{\mathrm{w}}+h_{\mathrm{r}, \mathrm{c}-\mathrm{s}}\right)},
$$

from (5) that

$$
T_{\mathrm{ap}}=\frac{S\left(A_{\mathrm{h}} / A_{\mathrm{a}}\right)+\left(h_{\mathrm{c}, \mathrm{ap}-\mathrm{c}}+h_{\mathrm{r}, \mathrm{ap}-\mathrm{c}}\right)\left(T_{\mathrm{c}}\right)+\left(h_{\mathrm{r}, \mathrm{ap}-\mathrm{j}}\right)\left(T_{\mathrm{j}}\right)+\left(h_{\mathrm{c}, \mathrm{ap}-\mathrm{a} 2}\right)\left(T_{\mathrm{o} 1}\right)}{\left(h_{\mathrm{c}, \mathrm{ap}-\mathrm{c}}+h_{\mathrm{r}, \mathrm{ap}-\mathrm{c}}+h_{\mathrm{r}, \mathrm{ap}-\mathrm{j}}+h_{\mathrm{c}, \mathrm{ap}-\mathrm{a} 2}\right)},
$$

from (6) that

$$
T_{\mathrm{o} 1}=\frac{\dot{m}_{1}\left(T_{\mathrm{A}}\right)+h_{\mathrm{c}, \mathrm{j}-\mathrm{a} 1}\left(T_{\mathrm{j}}-T_{\mathrm{a}}\right)+h_{\mathrm{c}, \mathrm{b}-\mathrm{a} 1}\left(T_{\mathrm{b}}-T_{\mathrm{a}}\right)}{C_{\mathrm{p}} \dot{m}_{1}},
$$

from (7) that

$$
T_{\mathrm{o}}=\frac{\dot{m}_{1}\left(T_{\mathrm{o} 1}\right)+h_{\mathrm{c}, \mathrm{j}-\mathrm{a} 2}\left(T_{\mathrm{j}}-T_{\mathrm{o} 1}\right)\left(A_{\mathrm{h}}\right)+h_{\mathrm{c}, \mathrm{ap}-\mathrm{a} 2}\left(T_{\mathrm{ap}}-T_{\mathrm{o} 1}\right)\left(A_{\mathrm{a}}\right)}{C_{\mathrm{p}} \dot{m}_{1}},
$$

from (8) that

$$
T_{\mathrm{j}}=\frac{\left(h_{\mathrm{r}, \mathrm{ap}-\mathrm{j}} T_{\mathrm{ap}}\right) *\left(A_{\mathrm{a}} / A_{\mathrm{h}}\right)+\left(h_{\mathrm{c}, \mathrm{j}-\mathrm{a} 2} T_{\mathrm{o} 1}\right)+\left(h_{\mathrm{c}, \mathrm{j}-\mathrm{a} 1} T_{\mathrm{a}}\right)+\left(h_{\mathrm{r}, \mathrm{j}-\mathrm{bp}} T_{\mathrm{bp}}\right)}{h_{\mathrm{c}, \mathrm{j}-\mathrm{a} 2}+h_{\mathrm{c}, \mathrm{j}-\mathrm{a} 1}+h_{\mathrm{r}, \mathrm{j}-\mathrm{bp}}+\left(\left(A_{\mathrm{a}} / A_{\mathrm{h}}\right) * h_{\mathrm{r}, \mathrm{ap}-\mathrm{j}}\right)},
$$



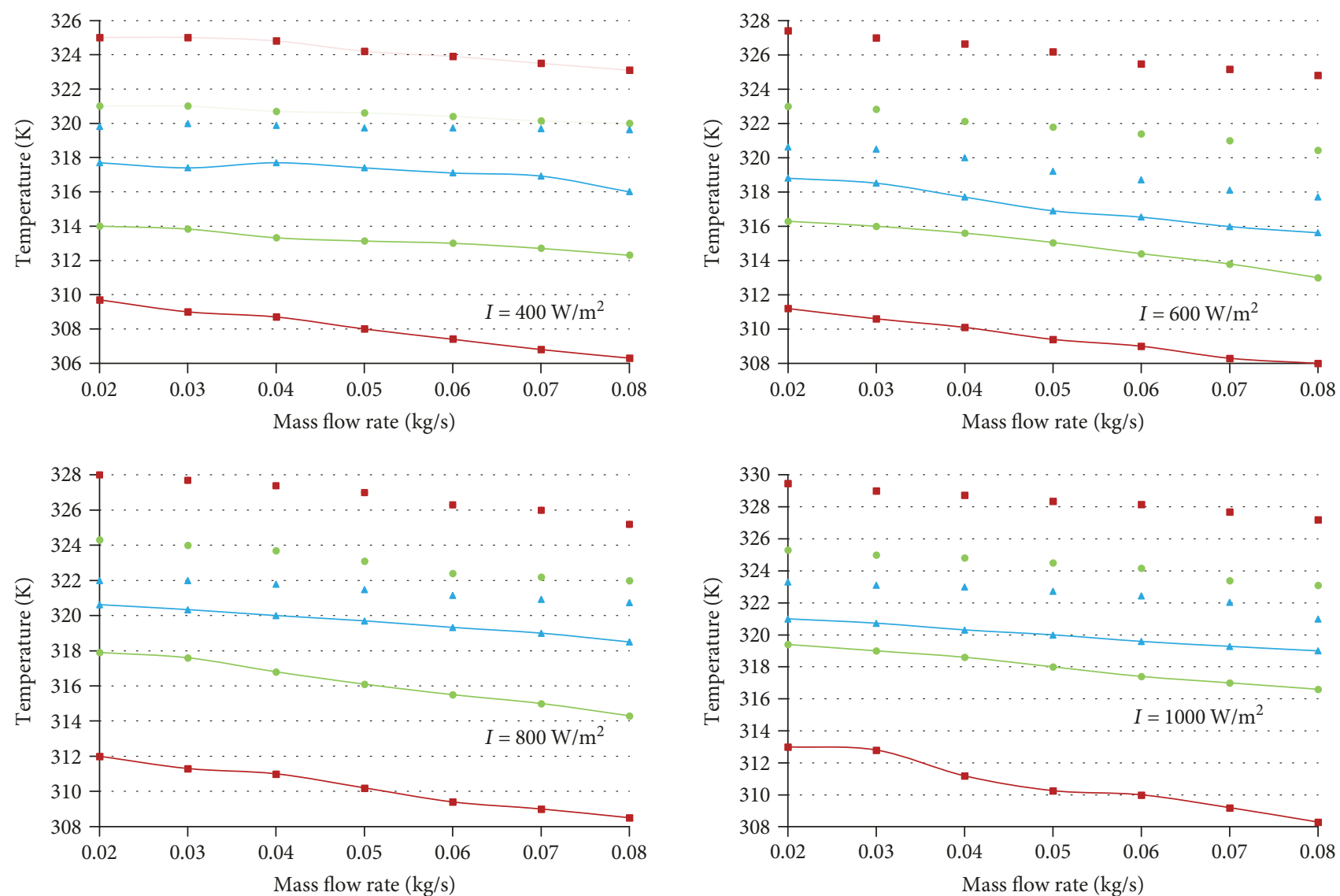

\begin{tabular}{|c|c|}
\hline e) & $T_{\text {ap }}$ (jet on a corrugated plate) \\
\hline o (jet on a & - $T_{\mathrm{ap}}$ (jet on a flat plate) \\
\hline (cross-cor & $T_{\text {ap }}$ (cross-corrugated plate) \\
\hline
\end{tabular}

Figure 16: Absorber plate and outlet temperature of different collector designs versus mass flow rate for different solar radiation levels.

and from (9) that

$$
T_{\mathrm{bp}}=\frac{\left(h_{\mathrm{b}} T_{\mathrm{A}}\right)+\left(h_{\mathrm{r}, \mathrm{j}-\mathrm{bp}} T_{\mathrm{j}}\right)+\left(h_{\mathrm{c}, \mathrm{a} 1-\mathrm{bp}} T_{\mathrm{a}}\right)}{\left(h_{\mathrm{b}}\right)+\left(h_{\mathrm{r}, \mathrm{j}-\mathrm{bp}}\right)+\left(h_{\mathrm{c}, \mathrm{a} 1-\mathrm{bp}}\right)} .
$$

The efficiency of solar heat gain of the heater is obtained as in [37].

$$
\eta=\frac{C_{\mathrm{p}}\left(\dot{m}_{1}\right)\left(T_{\mathrm{o}}-T_{\mathrm{i}}\right)}{I * A_{\mathrm{h}}}
$$

$h_{\mathrm{w}}$ is recommended by $[40]$ as

$$
h_{\mathrm{w}}=5.7+3.8 V_{\mathrm{w}}
$$

where $V_{\mathrm{w}}(\mathrm{m} / \mathrm{s})$ is the wind velocity of the ambient air and it is usually assumed that $V_{\mathrm{w}}=1.5 \mathrm{~m} / \mathrm{s}, h_{\mathrm{w}}=11.4 \mathrm{~W} / \mathrm{m}^{2} \mathrm{~K}$.

$h_{\mathrm{r}, \mathrm{c}-\mathrm{s}}$ is given as in [41]

$$
h_{\mathrm{r}, \mathrm{c}-\mathrm{s}}=\left(T_{\mathrm{c}}+T_{\mathrm{s}}\right)\left(T_{\mathrm{c}}^{2}+T_{\mathrm{s}}^{2}\right) \frac{\left(T_{\mathrm{c}}-T_{\mathrm{s}}\right)}{\left(T_{\mathrm{c}}-T_{\mathrm{a}}\right)},
$$

where $\sigma=5.67 \times 10^{-8} \mathrm{~W} / \mathrm{m}^{2} \mathrm{~K}^{4}$ is the Stefan-Boltzmann constant and the sky temperature $T_{\mathrm{s}}(\mathrm{K})$ is estimated by the formulation given by [42]

$$
T_{\mathrm{s}}=0.0552 T_{\mathrm{a}}^{1.5}
$$

The radiation heat transfer is given as in [37].

$$
\begin{gathered}
h_{\mathrm{r}, \mathrm{ap}-\mathrm{c}}=\frac{\sigma\left(T_{\mathrm{ap}}^{2}+T_{\mathrm{c}}^{2}\right)\left(T_{\mathrm{ap}}+T_{\mathrm{c}}\right)}{\left(1 / \epsilon_{\mathrm{ap}}\right)+\left(1 / \epsilon_{\mathrm{c}}\right)-1}, \\
h_{\mathrm{r}, \mathrm{ap}-\mathrm{j}}=\frac{\sigma\left(T_{\mathrm{ap}}^{2}+T_{\mathrm{j}}^{2}\right)\left(T_{\mathrm{ap}}+T_{\mathrm{j}}\right)}{\left(1 / \epsilon_{\mathrm{ap}}\right)+\left(1 / \epsilon_{\mathrm{j}}\right)-1}, \\
h_{\mathrm{r}, \mathrm{j}-\mathrm{bp}}=\frac{\sigma\left(T_{\mathrm{j}}^{2}+T_{\mathrm{bp}}^{2}\right)\left(T_{\mathrm{j}}+T_{\mathrm{bp}}\right)}{\left(1 / \epsilon_{\mathrm{j}}\right)+\left(1 / \epsilon_{\mathrm{bp}}\right)-1}, \\
h_{\mathrm{c}, \mathrm{ap}-\mathrm{a} 2}=\left(h_{\mathrm{r}, \mathrm{ap}-\mathrm{j}}\right) * \frac{\left(T_{\mathrm{ap}}-T_{\mathrm{o} 1}\right)}{\left(T_{\mathrm{ap}}-T_{\mathrm{a}}\right)} .
\end{gathered}
$$



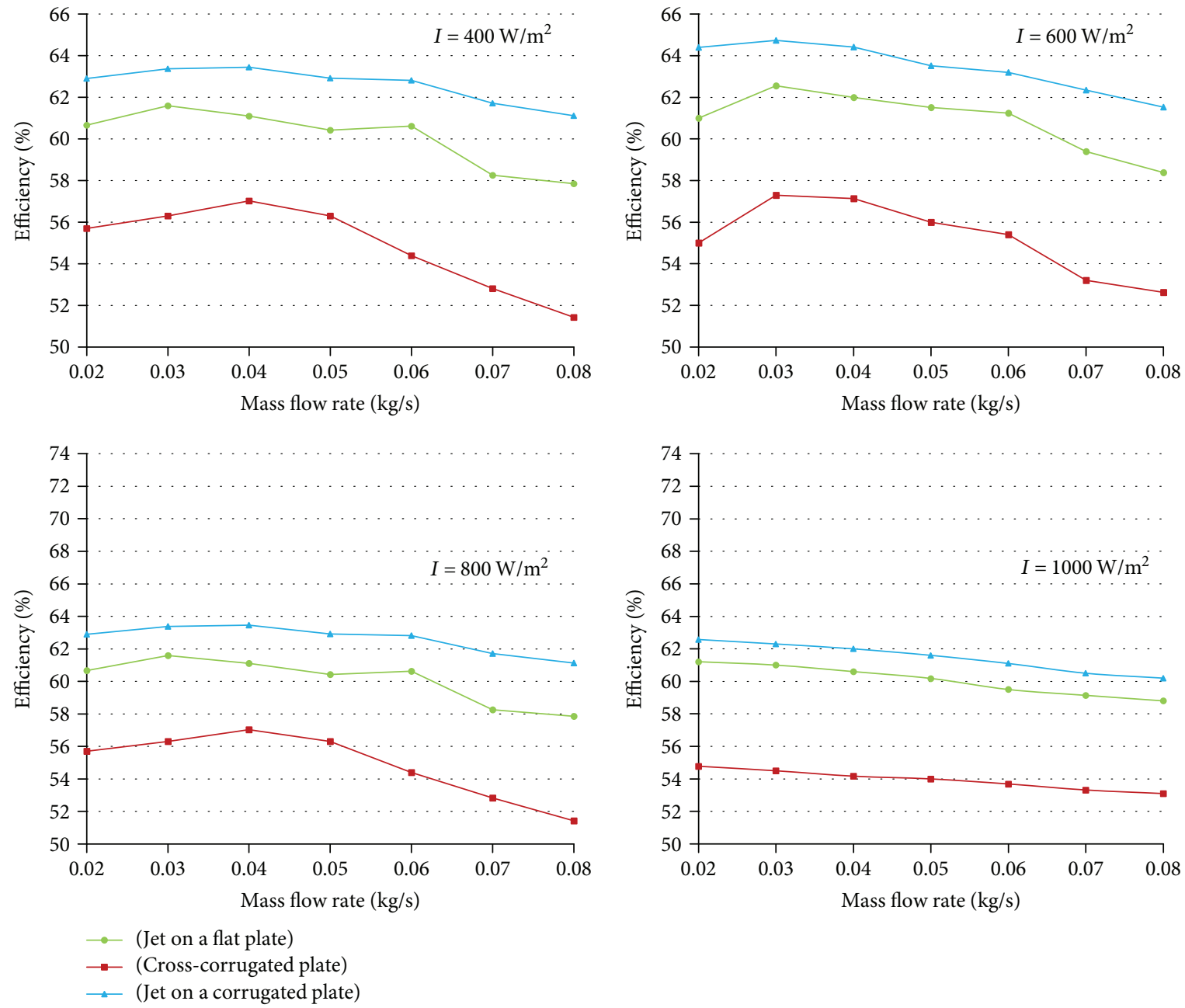

FIGURE 17: SAH Efficiency under the purview of three collector designs versus mass flow rate for different solar radiation levels.

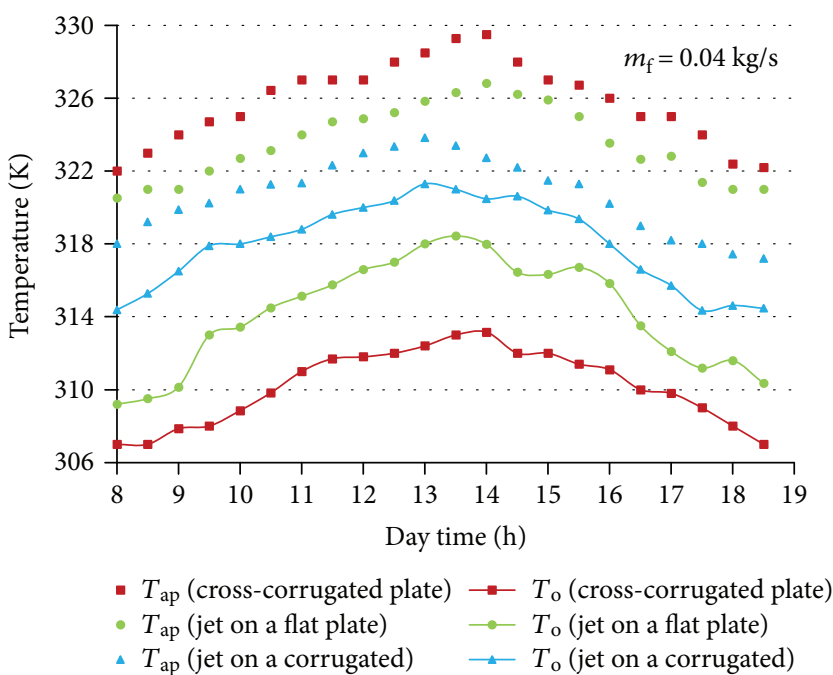

(a)

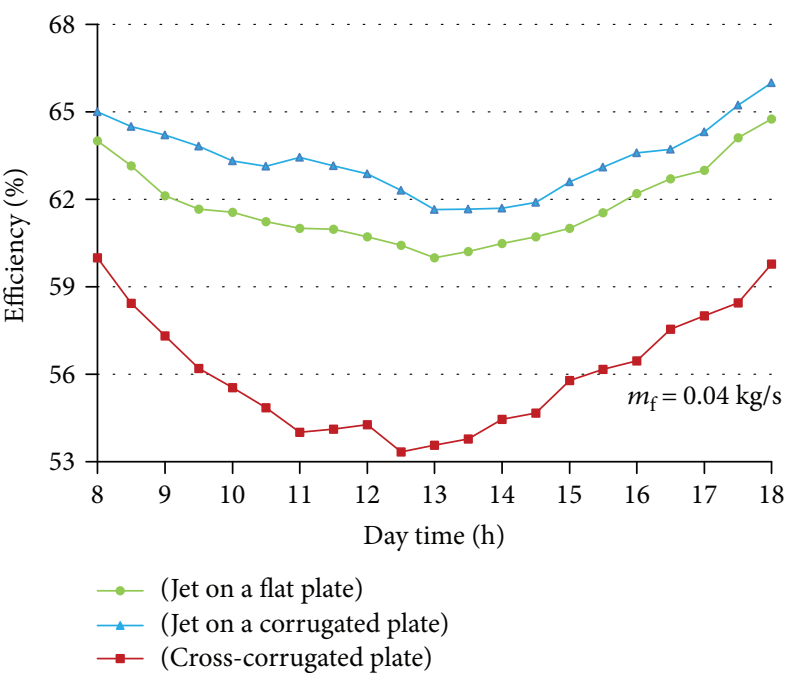

(b)

FIGURE 18: Hourly performance parameters under the purview of three designs of solar air heater. (a) Absorber plate temperature and air outlet temperature. (b) Collector efficiency. 


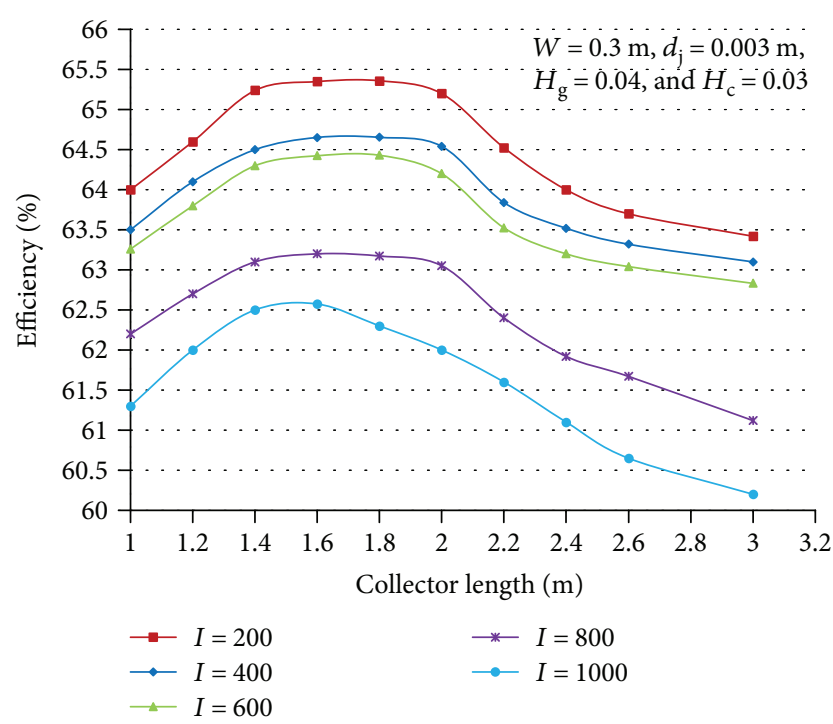

(a)

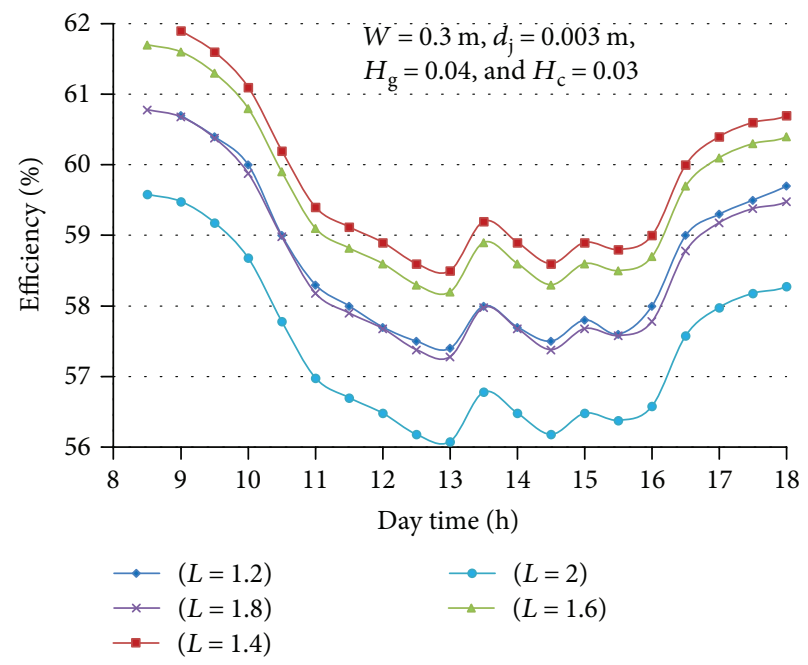

(b)

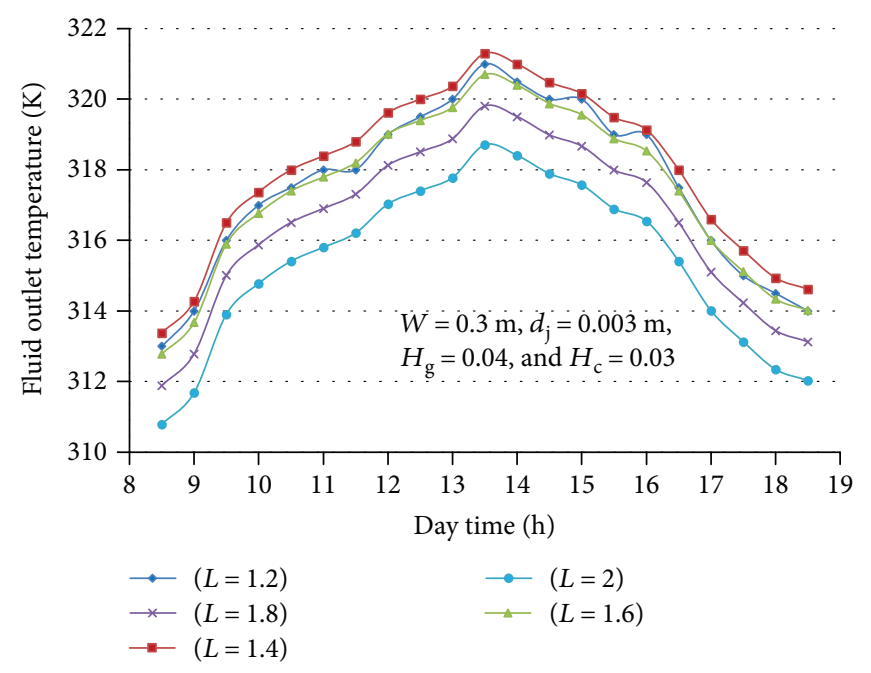

(c)

FIGURE 19: Prediction of the optimum length (L) of the proposed solar air heater. (a) SAH efficiency versus collector length at different solar radiation levels. (b) Hourly SAH efficiency over daytime at different collector lengths. (c) Hourly air outlet temperature at different collector lengths.

The conduction heat transfer coefficient across the insulation is estimated by

$$
h_{\mathrm{b}}=\frac{k_{\mathrm{i}}}{b}
$$

where $k_{\mathrm{i}}(\mathrm{W} / \mathrm{m} \mathrm{K})$ is the thermal conductivity of the insulation and $b(\mathrm{~m})$ is the mean thickness of the insulation.

The convection heat transfer coefficient between the glass cover and the absorbing plate is calculated by

$$
h_{\mathrm{c}, \mathrm{ap}-\mathrm{c}}=\mathrm{Nu}_{\mathrm{ap}-\mathrm{c}} \frac{K}{H_{\mathrm{c}}} .
$$

And $\mathrm{Nu}_{\mathrm{ap}-\mathrm{c}}$ is the Nusselt number for natural convection in the channel formed by the cover and the absorbing plate and is given as in [37]

$$
\mathrm{Nu}_{\mathrm{ap}-\mathrm{c}}=0.1673(\mathrm{Ra} * \cos \theta)^{0.2917},
$$

where $\theta\left(^{\circ}\right)$ is the angle of inclination of the heater and $\mathrm{Ra}$ is the Rayleigh number which is defined as

$$
\mathrm{Ra}=\frac{\rho^{2} c_{p} g \beta\left(T_{\mathrm{ap}}-T_{\mathrm{c}}\right) H_{\mathrm{c}}^{3}}{K_{\mu}}
$$

in which $\rho\left(\mathrm{kg} / \mathrm{m}^{3}\right), \beta(1 / \mathrm{K})$, and $\mu(\mathrm{kg} / \mathrm{ms})$ are the density, thermal expansion coefficient, and dynamic viscosity of air and $g\left(\mathrm{~m} / \mathrm{s}^{2}\right)$ is the acceleration due to gravity.

$$
\mathrm{Nu}_{\text {ap-f }}=0.0743 \mathrm{Re}^{0.76}
$$



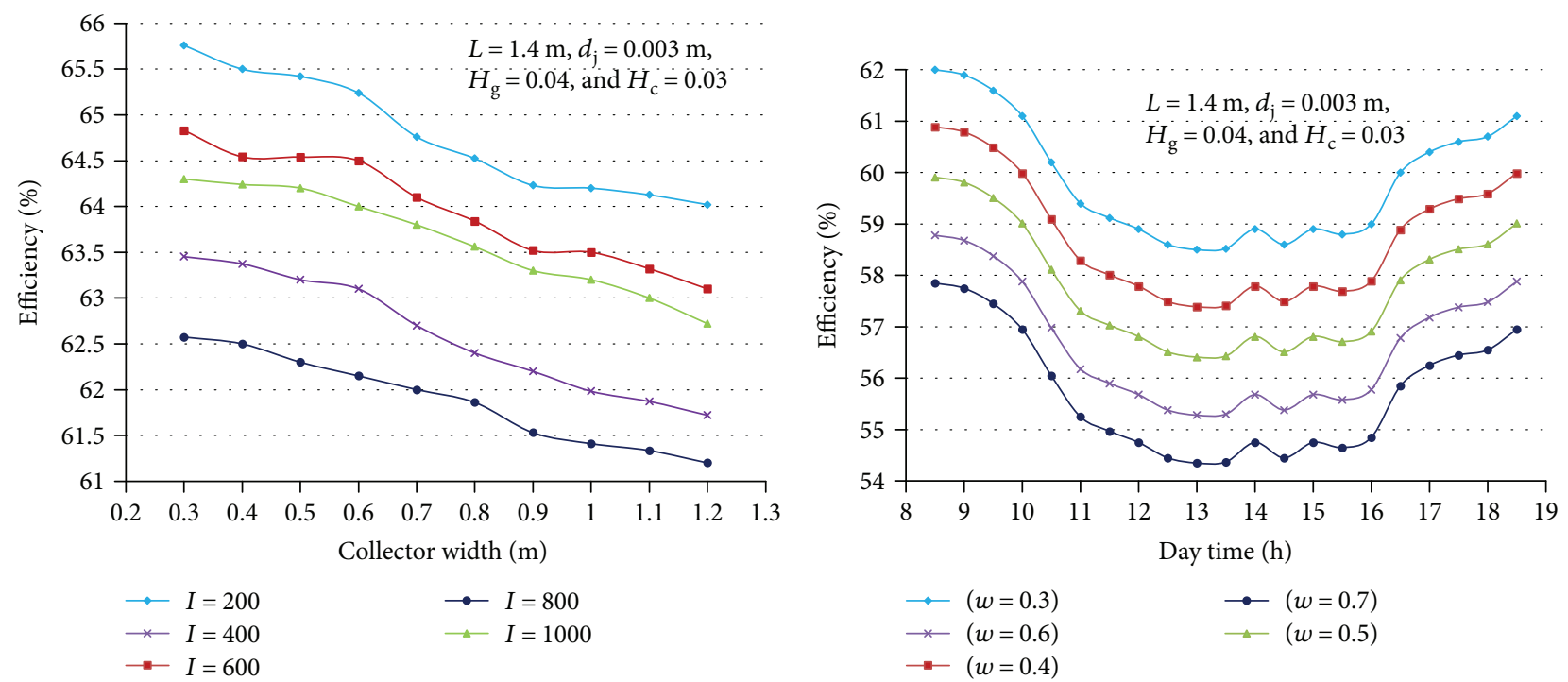

(a)

(b)

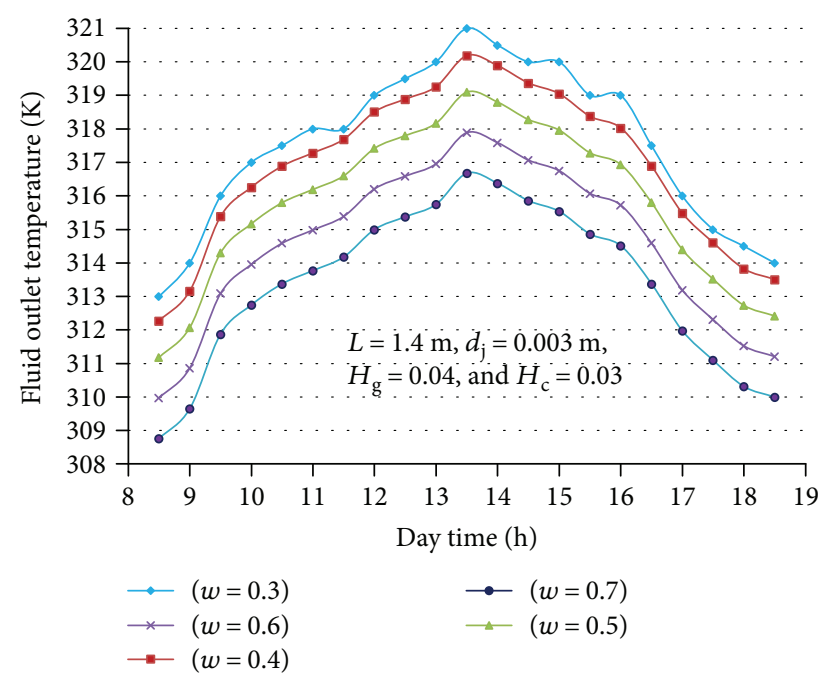

(c)

FIGURE 20: Prediction of the optimum width (W) of the proposed solar air heater. (a) SAH efficiency versus collector width at different solar radiation levels. (b) Hourly SAH efficiency over daytime at different collector widths. (c) Hourly air outlet temperature at different collector widths.

where Re is the Reynolds number, defined as follows:

$$
\operatorname{Re}=\frac{\rho \overline{V_{\mathrm{f}}} D_{\mathrm{h}}}{\mu},
$$

where $\overline{V_{\mathrm{f}}}(\mathrm{m} / \mathrm{s})$ is the mean velocity of fluid in the channel.

\section{Validation of the Proposed Mathematical Model}

The equations and procedures were used to predict the results of $[36,37]$ under their reported working conditions/ assumptions, as per Tables 1 and 2, respectively, for the purpose of validating the proposed mathematical model.

Figures 14(a)-14(c) show the comparison between the temperatures of the absorber plates, the bottom plate, and glass cover plate of the $\mathrm{SAH}$ and the fluid temperature gradient and SAH efficiency predicted by the proposed mathematical model and that in [36], while Figure 15 shows the comparison between outlet temperature and the efficiency of the SAH predicted by the proposed mathematical model and that in [37]. The values predicted by the proposed mathematical model are represented in the graph with discrete lines, while the results obtained from the aforementioned references are represented in the graph by continuous lines.

Figures 14 and 15 display excellent agreements between the values predicted by the proposed model and those reported in literature by the two aforementioned references. A statistical test was applied using the EFF test to further affirm the agreement between these values, and the results of the statistical test is tabulated in Table 4, falling between 27 and $99 \%$ for the many evaluation parameters. 


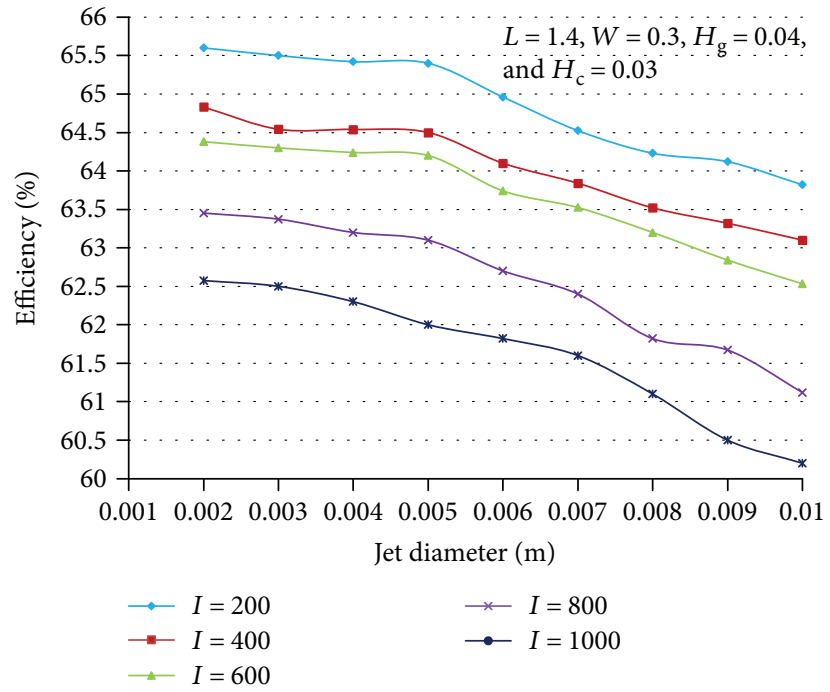

(a)

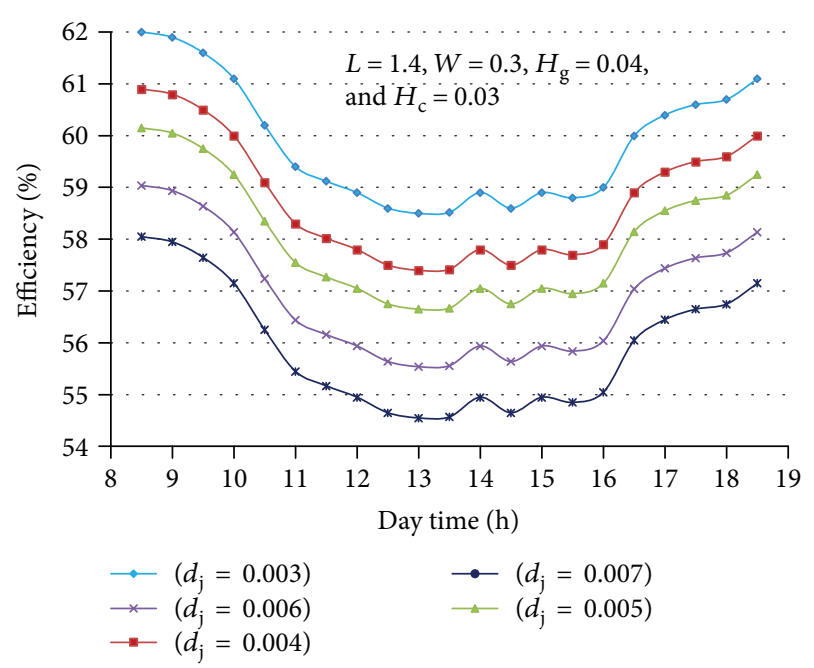

(b)

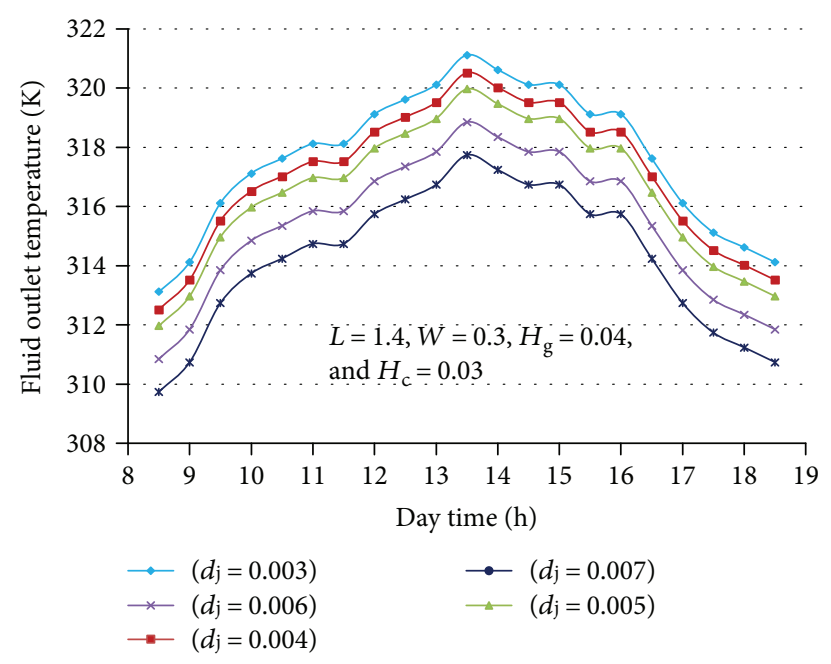

(c)

Figure 21: Prediction of the optimum jet diameter $\left(d_{\mathrm{j}}\right)$ of the proposed solar air heater. (a) SAH efficiency versus jet diameter at different solar radiation levels. (b) Hourly SAH efficiency over daytime at different jet diameters. (c) Hourly air outlet temperature at different jet diameters.

Based on the plots in Figures 14 and 15 and the values tabulated in Table 4, it can be confirmed that the proposed mathematical model is suitable for the prediction of the thermal performance parameters of the SAH.

\section{Potential of the Proposed SAH as a Superior Design}

This section details the comparison between the proposed SAH with jet impingement on the corrugated absorber plate to the jet-to-flat plate SAH and the cross-corrugated absorber plate SAH. The potential of the proposed SAH with respect to these aforementioned designs will be measured using the following evaluation parameters: temperature difference between fluid outlet and absorber plate, collector efficiency, and statistical paired $t$-test, and the working conditions/ assumptions that are used as input data in the three $\mathrm{SAH}$ designs are tabulated in Table 3.

5.1. Effect of Different SAH Designs on the Temperature of the Fluid Outlet and Absorber Plate. Figure 16 shows the temperature of the fluid outlet and absorber plate at different mass flow rates for multiple solar radiation for a total of $3 \mathrm{SAH}$ designs. The absorber plate's temperature is represented by discrete lines, while the fluid outlet's temperature is represented by continuous lines. It can be seen that the mass flow rate is inversely proportional to the temperature of the absorber plate and the fluid outlet, while it is also evident that the temperature of the absorber plate and fluid outlet is directly proportional to the solar radiation in the context of any mass flowrate. The highest temperature is achieved at solar radiation of $1000 \mathrm{~W} / \mathrm{m}^{2}$ and at mass flow rate falling between 0.02 and $0.04 \mathrm{~kg} / \mathrm{s}$. Figure 16 shows that the 


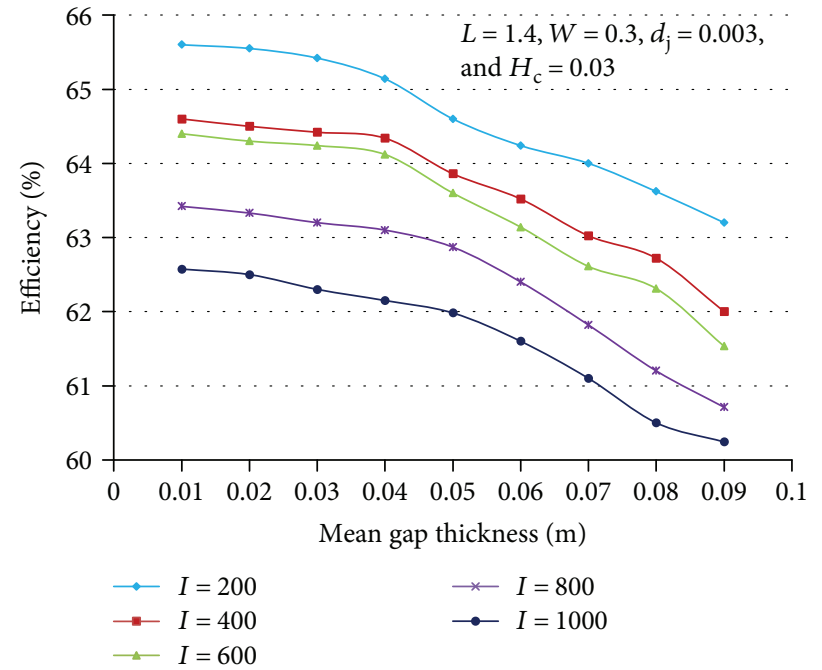

(a)

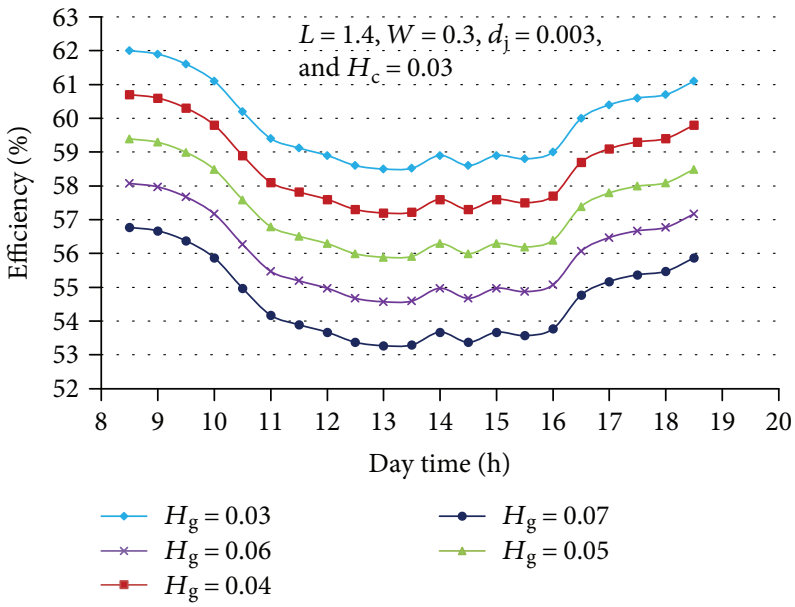

(b)

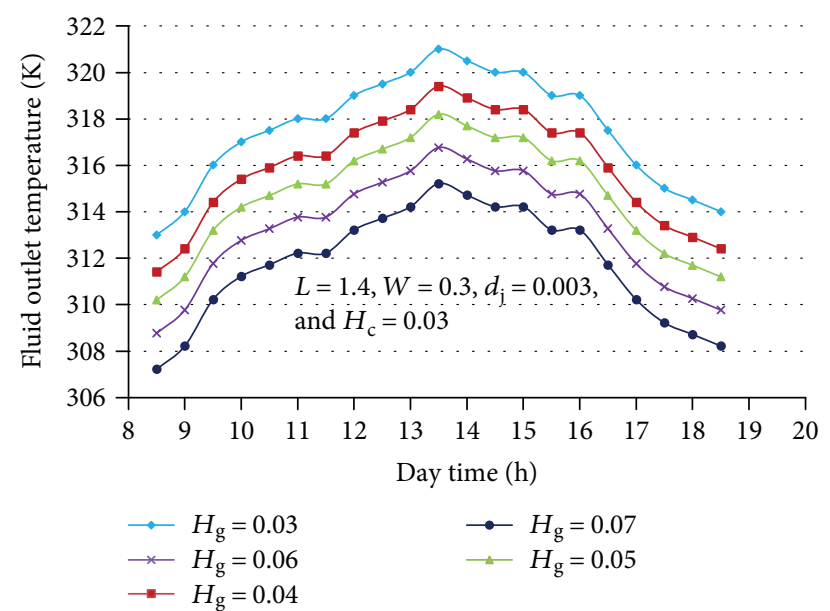

(c)

FIGURE 22: Prediction of the optimum mean gap thickness between the absorber plate and the jet plate $\left(H_{\mathrm{g}}\right)$ of the proposed solar air heater. (a) SAH efficiency versus $H_{\mathrm{g}}$ at different solar radiation levels. (b) Hourly SAH efficiency over daytime at different $H_{\mathrm{g}}$. (c) Hourly air outlet temperature at different $H_{\mathrm{g}}$.

proposed SAH reported the highest fluid outlet temperature, followed by SAH with the jet-to-flat plate absorber, then $\mathrm{SAH}$ with the cross-corrugated plate. Simultaneously, the proposed SAH reported the lowest absorber plate temperature, followed by the SAH with the jet-to-flat plate absorber, then SAH with the cross-corrugated plate. It should be pointed out that the fluid outlet and absorber plate's temperatures of the proposed SAH converged significantly at temperature differences of less than $3 \mathrm{~K}$, which means that the proposed $\mathrm{SAH}$ design allowed the fluid outlet to gain highest heat from the corrugated absorber plate. Simultaneously, it was also shown that the fluid outlet and absorber plate temperatures for other designs remain beyond the desired convergence. Hence, it can be posited that the proposed design is superior for heat extraction when compared to the other designs.

\subsection{Effect of Different Collector Designs on SAH Efficiency.} Figure 17 shows the SAH efficiency at multiple mass flow rates for different solar radiation levels under the purview of three collector designs. It is evident that the mass flow rate or solar radiation is inversely proportional to SAH efficiency. The highest efficiency was reported to be within mass flowrate range $0.02-0.04 \mathrm{~kg} / \mathrm{s}$. It should be pointed out that as per Figure 17, the proposed SAH showed the highest efficiency, followed by the jet-to-flat plate absorber, then SAH with the cross-corrugated plate. As per Figures 16 and 17, we can confirm that the jet impingement on the corrugated absorber is the best SAH design compared to the others being studied.

\subsection{Hourly Thermal Performance of Different SAH Designs} under Clear Sky. The thermal performance of the designs is plotted hourly during daytime on a clear sky day. Figure 18(a) shows the hourly fluid outlet temperature and absorber plate temperature of different $\mathrm{SAH}$ designs at a mass flow rate $m_{\mathrm{f}}=0.04 \mathrm{~kg} / \mathrm{s}$. The absorber plate temperature is represented by discrete lines, while fluid outlet temperature is represented by continuous lines. The results 


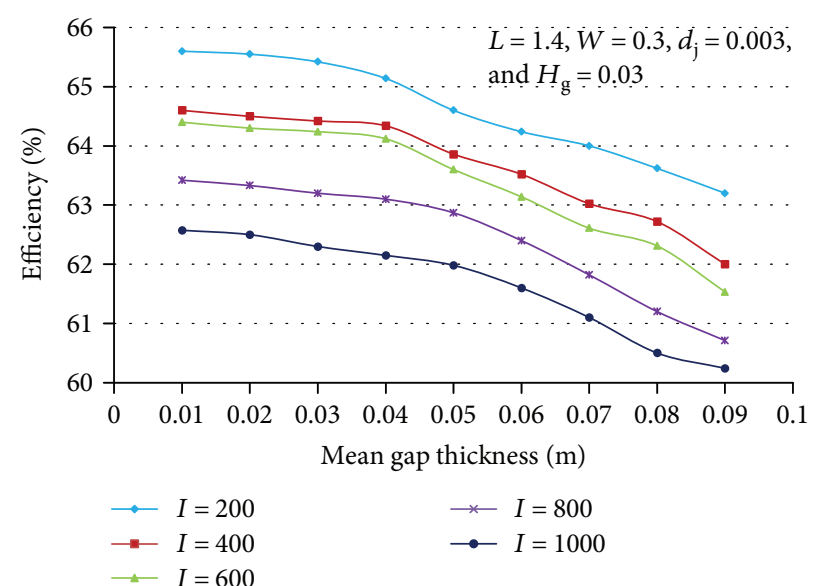

(a)

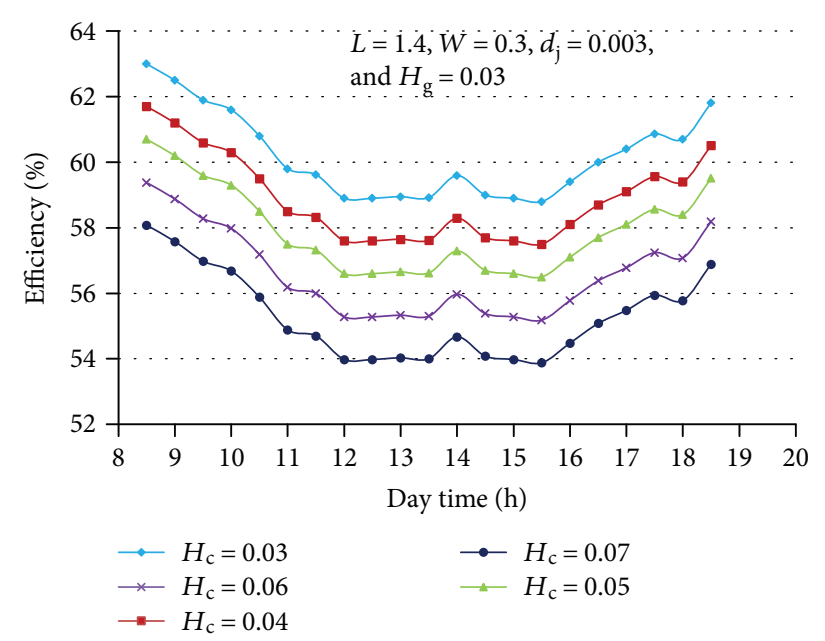

(b)

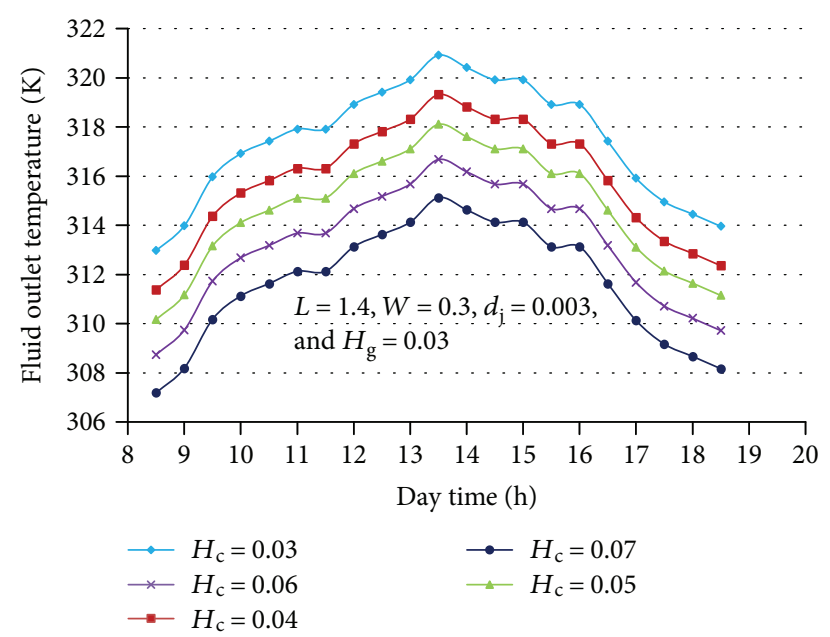

(c)

FIGURE 23: Prediction of the optimum mean gap thickness between the absorber plate and the glass cover $\left(H_{c}\right)$ of the proposed solar air heater. (a) SAH efficiency versus $H_{\mathrm{c}}$ at different solar radiation levels. (b) Hourly SAH efficiency over daytime at different $H_{\mathrm{c}}$. (c) Hourly air outlet temperature at different $H_{c}$.

showed that the min-max fluid outlet temperatures during the day for the proposed SAH, jet-to-flat plate $\mathrm{SAH}$, and cross-corrugated plate SAH are $314-321 \mathrm{~K}, 309.5-317 \mathrm{~K}$, and $307-313 \mathrm{~K}$, respectively. It can also be seen that the min-max absorber plate temperatures during a clear sky day for the proposed SAH, jet-to-flat plate SAH, and crosscorrugated plate SAH are $317-323.5 \mathrm{~K}, 319-326.5 \mathrm{~K}$, and $322-328 \mathrm{~K}$, respectively. It was seen that the maximum temperature difference between the absorber plate and fluid outlet for the proposed SAH, jet-to-flat plate SAH, and the crosscorrugated plate $\mathrm{SAH}$ is $\sim 3 \mathrm{~K}, 9 \mathrm{~K}$, and $15 \mathrm{~K}$, respectively.

Figure 18(b) shows the efficiency of multiple $\mathrm{SAH}$ designs at a mass flowrate $m_{\mathrm{f}}=0.04 \mathrm{~kg} / \mathrm{s}$. It can be seen that the min-max efficiencies for the proposed $\mathrm{SAH}$, jetto-flat plate $\mathrm{SAH}$, and the cross-corrugated plate $\mathrm{SAH}$ are 61.5-65.7, 60-64.8, and 53.6-60\%, respectively. As per Figures 18(a) and 18(b), it is evident that the thermal performance of the proposed SAH during the day was significantly enhanced compared to the cross-corrugated plate SAH and the jet on a flat plate SAH. This enhancement of the proposed SAH vis-à-vis the jet-to-flat plate SAH needs to be accurately ascertained via statistical test. The paired $t$-test was used to determine whether the efficiency enhancement of the proposed SAH can be regarded as significant vis-à-vis the jet-to-flat plate $\mathrm{SAH}$. It was found that the statistical paired $t$-test proved that the efficiency enhancement is significant.

\section{Parametric Performance Optimization of the Proposed SAH}

In this round of analyses, the optimal values of the design parameters of SAH are going to be determined. The investigated ranges of parameters are $1-3 \mathrm{~m}$ for the collectors' length, $0.3-1.2 \mathrm{~m}$ for the collectors' width, $0.002-0.01 \mathrm{~m}$ for the jet diameter, and $0.01-0.09 \mathrm{~m}$ for the mean gap thickness between the absorbing plate and the jet plate.

6.1. Optimum Collector Length of the Proposed SAH. The influence of collector length $(L)$ upon the efficiency of the 
SAH at multiple solar radiation values are detailed in Figure 19(a). Generally, at any solar radiation value, the collector length is directly proportional to the SAH efficiency, up till the point where the collector length reaches $1.4-2 \mathrm{~m}$, where at this point, the efficiency is inversely proportional to the collectors' length. In order to pinpoint the exact optimal collector length, the hourly SAH efficiency and hourly fluid outlet temperature were predicted during a clear sky day and plotted against multiple collectors' length, as per Figures 19(b) and 19(c). The results showed that the optimal collector length showing maximum efficiency and maximum fluid outlet temperature concurrently is $1.4 \mathrm{~m}$.

6.2. Optimum Collector Width of SAH. The effect of the collectors' width $(W)$ on the efficiency of the SAH at multiple solar radiation values is detailed in Figure 20(a). Generally, at each solar radiation value, it can be seen that the collectors' width is inversely proportional to the efficiency of the SAH. The hourly SAH efficiency and hourly fluid outlet temperature predicted during a clear sky day were plotted at multiple collector widths, as per Figures 20(b) and 20(c). The optimum collector width indicating maximum efficiency and maximum fluid outlet temperature concurrently is $W=0.3 \mathrm{~m}$.

6.3. Optimum Jet Diameter $\left(d_{j}\right)$. The effect of jet diameter $\left(d_{\mathrm{j}}\right)$ on the efficiency of the SAH at multiple solar radiation values is detailed in Figure 21(a). At multiple solar radiation values, the range of jet diameter between 0.002 and $0.005 \mathrm{~m}$ showed almost maximum efficiency; thereafter, the SAH efficiency started gradually decreasing as jet diameter increases. In order to pinpoint the exact optimal jet diameter, the hourly SAH efficiency and hourly fluid outlet temperature were predicted and plotted against multiple jet diameter values, as per Figures 21(b) and 21(c). The results showed that the optimum jet diameter showing maximum SAH efficiency and maximum fluid outlet temperature concurrently is $0.003 \mathrm{~m}$.

6.4. Optimum Mean Gap Thickness between the Absorbing Plate and the Jet Plate $\left(H_{g}\right)$. The influence of $H_{\mathrm{g}}$ upon SAH efficiency at multiple solar radiation values is illustrated in Figure 22(a). The range of mean gap thickness that realizes maximum efficiency at multiple solar radiation falls within 0.01-0.04 m; thereafter, it starts demonstrating an inverse relationship with the mean gap thickness. In order to precisely determine the optimal mean gap thickness, the hourly SAH efficiency and hourly fluid outlet temperature are plotted at multiple mean gap thicknesses and are shown in Figures 22(b) and 22(c). It was seen that the optimum mean gap thickness showing maximum SAH efficiency and maximum fluid outlet temperature concurrently is $0.3 \mathrm{~m}$.

6.5. Optimum Mean Gap Thickness between the Absorbing Plate and the Glass Cover $\left(H_{c}\right)$. The influence of $H_{c}$ upon the efficiency of the SAH at different solar radiation values is presented in Figure 23(a). The range of the mean gap thickness that realizes maximum efficiency at multiple solar radiation falls within $0.01-0.04 \mathrm{~m}$; thereafter, it becomes inversely related to the mean gap thickness. In order to precisely determine the optimal mean gap thickness, the hourly SAH efficiency and hourly fluid outlet temperature seen during a clear sky day are plotted against multiple mean gap thicknesses, as per Figures 23(b) and 23(c). It was shown that the optimal mean gap thickness showing maximum SAH efficiency and maximum fluid outlet temperature concurrently is $0.3 \mathrm{~m}$.

\section{Conclusions}

This study involves the development of an energy balance model of the proposed design of SAH and comparing it to two previously reported SAH designs. The improvement to the thermal performance of the proposed SAH was evaluated in the context of fluid outlet temperature, temperature difference between the fluid outlet and absorber plate, and thermal efficiency. The proposed SAH reported the highest fluid outlet temperature and efficiency, followed by the $\mathrm{SAH}$ with the jet on the flat plate absorber and the SAH with the cross-corrugated plate, respectively. The fluid outlet and absorber plate temperatures of the proposed $\mathrm{SAH}$ converged significantly when close to a temperature difference of less than $3 \mathrm{~K}$. Moreover, the statistical paired $t$-test results reported significant differences in the mean values of the SAH efficiency pre and postmodifications. It can be concluded that the proposed design significantly improved the thermal performance of SAH.

\section{Abbreviations}

\begin{tabular}{|c|c|}
\hline$L:$ & Length of heater $(\mathrm{m})$ \\
\hline$W:$ & Width of heater (m) \\
\hline$H_{\mathrm{g}}:$ & $\begin{array}{l}\text { Mean gap thickness between the absorbing plate } \\
\text { and the jet plate }(\mathrm{m})\end{array}$ \\
\hline$A_{\mathrm{a}}:$ & Absorber area $\left(\mathrm{m}^{2}\right)$ \\
\hline$A_{\mathrm{h}}:$ & Heater area $\left(\mathrm{m}^{2}\right)$ \\
\hline$d_{\mathrm{j}}:$ & Jet diameter $(\mathrm{m})$ \\
\hline I: & $\begin{array}{l}\text { Solar insulation rate incident on the glass cover } \\
\left(\mathrm{W} / \mathrm{m}^{2}\right)\end{array}$ \\
\hline$V_{\mathrm{w}}:$ & Wind velocity of the ambient air $(\mathrm{m} / \mathrm{s})$ \\
\hline$\tau_{c}:$ & Transmissivity of the glass cover \\
\hline$\alpha_{\mathrm{ap}}:$ & Absorptivity of the absorbing plate \\
\hline$\eta:$ & Efficiency of the air heater \\
\hline S: & $\begin{array}{l}\text { Solar radiation absorbed by the absorbing plate per } \\
\text { unit area }\left(\mathrm{W} / \mathrm{m}^{2}\right)\end{array}$ \\
\hline$m_{\mathrm{f}}:$ & Air mass flow rate per unit area of heater $(\mathrm{kg} / \mathrm{s})$ \\
\hline$q_{\mathrm{u}}:$ & Useful energy gain $\left(\mathrm{W} / \mathrm{m}^{2}\right)$ \\
\hline$c_{\mathrm{p}}:$ & Specific heat of air $(\mathrm{kJ} / \mathrm{kg} \mathrm{K})$ \\
\hline$T_{\mathrm{a}}:$ & $\begin{array}{l}\text { Temperature of air flowing through channel above } \\
\text { bottom plate }(\mathrm{K})\end{array}$ \\
\hline$T_{\mathrm{f}}:$ & $\begin{array}{l}\text { Temperature of air flowing through channel above } \\
\text { jet plate }(\mathrm{K})\end{array}$ \\
\hline$T_{\mathrm{o} 1}:$ & $\begin{array}{l}\text { Outlet air temperature through jet, above jet } \\
\text { plate }(\mathrm{K})\end{array}$ \\
\hline$T_{\mathrm{o}}:$ & Outlet air temperature through heater $(\mathrm{K})$ \\
\hline$T_{\mathrm{ap}}:$ & Mean temperature of absorbing plate $(\mathrm{K})$ \\
\hline$T_{c}:$ & Mean temperature of the glass cover $(\mathrm{K})$ \\
\hline$T_{\mathrm{A}}:$ & Ambient temperature $(\mathrm{K})$ \\
\hline$h_{\mathrm{w}}:$ & $\begin{array}{l}\text { Convection heat transfer coefficient from glass } \\
\text { cover due to the wind }\left(\mathrm{W} / \mathrm{m}^{2} \mathrm{~K}\right)\end{array}$ \\
\hline
\end{tabular}


$h_{\mathrm{r}, \mathrm{c}-\mathrm{s}}$ : Radiation heat transfer coefficient between the cover and the sky $\left(\mathrm{W} / \mathrm{m}^{2} \mathrm{~K}\right)$

$h_{\mathrm{c}, \mathrm{f}-\mathrm{bp}}$ : Convection heat transfer coefficient between fluid and bottom plate $(\mathrm{W} / \mathrm{m} 2 \mathrm{~K})$

$h_{c, a p-f}$ Convection heat transfer coefficient between absorbing plate and the fluid $(\mathrm{W} / \mathrm{m} 2 \mathrm{~K})$

$h_{\mathrm{r}, \mathrm{ap}-\mathrm{bp}}$ : Radiation heat transfer coefficient between absorbing plate and the bottom plate $(\mathrm{W} / \mathrm{m} 2 \mathrm{~K})$

$h_{\mathrm{r}, \mathrm{ap}-\mathrm{c}}$ : Radiation heat transfer coefficient between glass cover and absorbing plate $\left(\mathrm{W} / \mathrm{m}^{2} \mathrm{~K}\right)$

$h_{c, \text { ap }} \mathrm{c}$ : Convection heat transfer coefficient between glass cover and absorbing plate $\left(\mathrm{W} / \mathrm{m}^{2} \mathrm{~K}\right)$

$k_{\mathrm{i}}: \quad$ Thermal conductivity of the insulation $(\mathrm{W} / \mathrm{m} \mathrm{K})$

$b$ : $\quad$ Mean thickness of the insulation (m).

\section{Conflicts of Interest}

The authors declare that they have no conflicts of interest.

\section{References}

[1] N. K. Bansal, "Solar air heater applications in India," Renewable Energy, vol. 16, no. 1-4, pp. 618-623, 1999.

[2] W. Gao, W. Lin, T. Liu, and C. Xia, "Analytical and experimental studies on the thermal performance of crosscorrugated and flat-plate solar air heaters," Applied Energy, vol. 84, no. 4, pp. 425-441, 2007.

[3] M. A. Wazed, Y. Nukman, and M. T. Islam, "Design and fabrication of a cost effective solar air heater for Bangladesh," Applied Energy, vol. 87, no. 10, pp. 3030-3036, 2010.

[4] K. Prasad and S. C. Mullick, "Heat transfer characteristics of a solar air heater used for drying purposes," Applied Energy, vol. 13, no. 2, pp. 83-93, 1983.

[5] J. C. Han, "Heat transfer and friction in channels with two opposite rib-roughened walls," Journal of Heat Transfer, vol. 106, no. 4, pp. 774-781, 1984.

[6] S. Singh, S. Chander, and J. S. Saini, "Heat transfer and friction factor of discrete V-down rib roughened solar air heater ducts," Journal of Renewable and Sustainable Energy, vol. 3, no. 1, article 013108, 2011.

[7] R. Chauhan and N. S. Thakur, "Heat transfer and friction factor correlations for impinging jet solar air heater," Experimental Thermal and Fluid Science, vol. 44, pp. 760-767, 2013.

[8] S. K. Verma and B. N. Prasad, "Investigation for the optimal thermohydraulic performance of artificially roughened solar air heaters," Renewable Energy, vol. 20, no. 1, pp. 19-36, 2000.

[9] A. M. Elbreki, M. A. Alghoul, A. N. Al-Shamani et al., "The role of climatic-design-operational parameters on combined $\mathrm{PV} / \mathrm{T}$ collector performance: a critical review," Renewable and Sustainable Energy Reviews, vol. 57, pp. 602-647, 2016.

[10] L. Goldstein and E. M. Sparrow, "Experiments on the transfer characteristics of a corrugated fin and tube heat exchanger configuration," Journal of Heat Transfer, vol. 98, no. 1, pp. 26-34, 1976.

[11] L. Goldstein and E. M. Sparrow, "Heat/mass transfer characteristics for flow in a corrugated wall channel," Journal of Heat Transfer, vol. 99, no. 2, pp. 187-195, 1977.

[12] M. Sethi and M. Sharma, "Effective efficiency prediction for discrete type of ribs used in solar air heaters," International Journal of Energy \& Environment, vol. 1, no. 2, pp. 333-342, 2010.
[13] D. Gupta, S. C. Solanki, and J. S. Saini, "Heat and fluid flow in rectangular solar air heater ducts having transverse rib roughness on absorber plates," Solar Energy, vol. 51, no. 1, pp. 31-37, 1993.

[14] R. P. Saini and J. S. Saini, "Heat transfer and friction factor correlations for artificially roughened ducts with expanded metal mesh as roughness element," International Journal of Heat and Mass Transfer, vol. 40, no. 4, pp. 973-986, 1997.

[15] R. Karwa, S. C. Solanki, and J. S. Saini, "Heat transfer coefficient and friction factor correlations for the transitional flow regime in rib-roughened rectangular ducts," International Journal of Heat and Mass Transfer, vol. 42, no. 9, pp. 15971615, 1999.

[16] J. L. Bhagoria, J. S. Saini, and S. C. Solanki, "Heat transfer coefficient and friction factor correlations for rectangular solar air heater duct having transverse wedge shaped rib roughness on the absorber plate," Renewable Energy, vol. 25, no. 3, pp. 341-369, 2002.

[17] R. Karwa and G. Chitoshiya, "Performance study of solar air heater having v-down discrete ribs on absorber plate," Energy, vol. 55, pp. 939-955, 2013.

[18] A. Kumar, R. P. Saini, and J. S. Saini, "Development of correlations for Nusselt number and friction factor for solar air heater with roughened duct having multi v-shaped with gap rib as artificial roughness," Renewable Energy, vol. 58, pp. 151-163, 2013.

[19] S. Saurav and V. N. Bartaria, "Heat transfer and thermal efficiency of solar air heater having artificial roughness: a review," International Journal of Renewable Energy Research, vol. 3, no. 3, pp. 498-508, 2013.

[20] B. A. Meyer, J. W. Mitchell, and M. M. El-Wakil, "Convective heat transfer in Vee-trough linear concentrators," Solar Energy, vol. 28, no. 1, pp. 33-40, 1982.

[21] X. W. Zhao and Z. N. Li, "Numerical and experimental study on free convection in air layers with one surface V-corrugated," in In Proceedings of the Annual Meeting of the Chinese Society of Solar Energy, vol. 1991, pp. 182-192, 1991.

[22] J. A. Stasiek, "Experimental studies of heat transfer and fluid flow across corrugated-undulated heat exchanger surfaces," International Journal of Heat and Mass Transfer, vol. 41, no. 6-7, pp. 899-914, 1998.

[23] Y. Piao, Natural, Forced and Mixed Convection in a Vertical Cross-Corrugated Channel, University of British Columbia, 1992, Doctoral dissertation.

[24] S. Noorshahi, C. A. Hall III, and E. K. Glakpe, "Natural convection in a corrugated enclosure with mixed boundary conditions," Journal of Solar Energy Engineering, vol. 118, no. 1 , pp. 50-57, 1996.

[25] W. Gao, Analysis and Performance of a Solar Air Heater with Cross Corrugated Absorber and Back-Plate [MSc Thesis], Yunnan Normal University, Kunming, 1996.

[26] A. A. El-Sebaii, S. Aboul-Enein, M. R. I. Ramadan, S. M. Shalaby, and B. M. Moharram, "Investigation of thermal performance of-double pass-flat and v-corrugated plate solar air heaters," Energy, vol. 36, no. 2, pp. 1076-1086, 2011.

[27] M. N. Metwally, H. Z. Abou-Ziyan, and A. M. El-Leathy, "Performance of advanced corrugated-duct solar air collector compared with five conventional designs," Renewable Energy, vol. 10, no. 4, pp. 519-537, 1997.

[28] T. Liu, W. Lin, W. Gao, and C. Xia, “A comparative study of the thermal performances of cross-corrugated and v-groove 
solar air collectors," International Journal of Green Energy, vol. 4, no. 4, pp. 427-451, 2007.

[29] J. C. Han, "Recent studies in turbine blade cooling," International Journal of Rotating Machinery, vol. 10, no. 6, pp. 443-457, 2004.

[30] M. K. Sung and I. Mudawar, "Experimental and numerical investigation of single-phase heat transfer using a hybrid jetimpingement/micro-channel cooling scheme," International Journal of Heat and Mass Transfer, vol. 49, no. 3-4, pp. 682694, 2006.

[31] M. RÃkger, R. Buck, and H. MÃžller-Steinhagen, "Numerical and experimental investigation of a multiple air jet cooling system for application in a solar thermal receiver," Journal of Heat Transfer, vol. 127, no. 8, pp. 863-876, 2005.

[32] N. Zuckerman and N. Lior, "Jet impingement heat transfer: physics, correlations, and numerical modeling," Advances in Heat Transfer, vol. 39, pp. 565-631, 2006.

[33] M. K. Sung and I. Mudawar, "Single-phase and two-phase hybrid cooling schemes for high-heat-flux thermal management of defense electronics," Journal of Electronic Packaging, vol. 131, no. 2, article 021013, 2009.

[34] M. Belusko, W. Saman, and F. Bruno, "Performance of jet impingement in unglazed air collectors," Solar Energy, vol. 82, no. 5, pp. 389-398, 2008.

[35] D. Klein and G. Hetsroni, "Enhancement of heat transfer coefficients by actuation against an impinging jet," International Journal of Heat and Mass Transfer, vol. 55, no. 15-16, pp. 4183-4194, 2012.

[36] W. Lin, W. Gao, and T. Liu, "A parametric study on the thermal performance of cross-corrugated solar air collectors," Applied Thermal Engineering, vol. 26, no. 10, pp. 1043-1053, 2006.

[37] C. Choudhury and H. P. Garg, "Evaluation of a jet plate solar air heater," Solar Energy, vol. 46, no. 4, pp. 199-209, 1991.

[38] D. G. Mayer and D. G. Butler, "Statistical validation," Ecological Modelling, vol. 68, no. 1-2, pp. 21-32, 1993.

[39] J. L. Hintze, "NCSS Statistical Software NCSS.com 208-1 () NCSS, LLC," 1981, Chapter 208 Paired T-Test.

[40] W. H. McAdams, "Heat transmission (No. 660.28427 M32)," 1954.

[41] X. Q. Zhai, Y. J. Dai, and R. Z. Wang, "Comparison of heating and natural ventilation in a solar house induced by two roof solar collectors," Applied Thermal Engineering, vol. 25, no. 5-6, pp. 741-757, 2005.

[42] W. C. Swinbank, "Long-wave radiation from clear skies," Quarterly Journal of the Royal Meteorological Society, vol. 89, no. 381, pp. 339-348, 1963. 

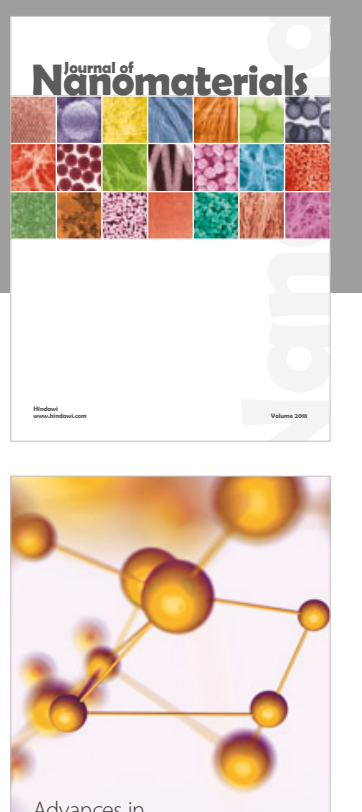

Physical Chemistry
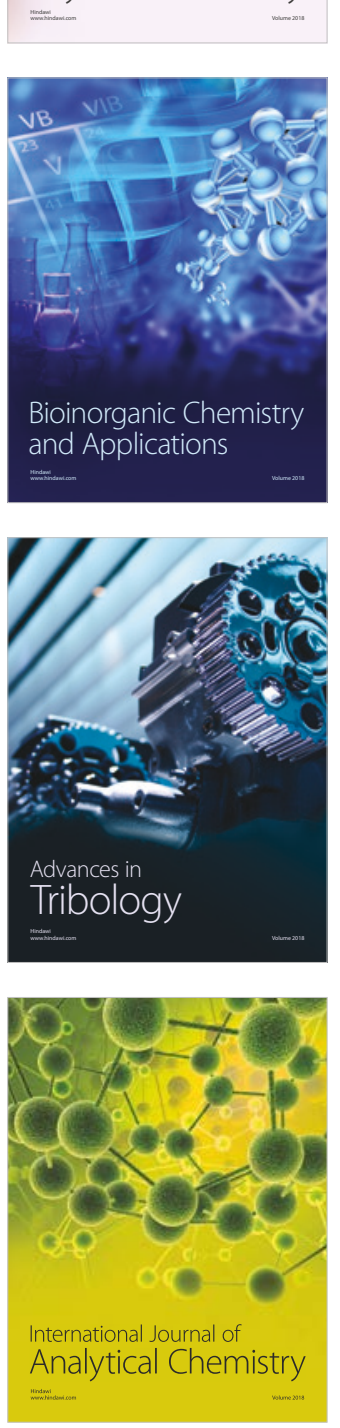

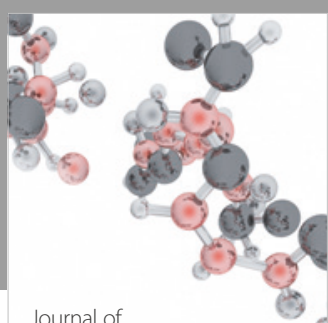

Analytical Methods

in Chemistry

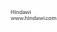

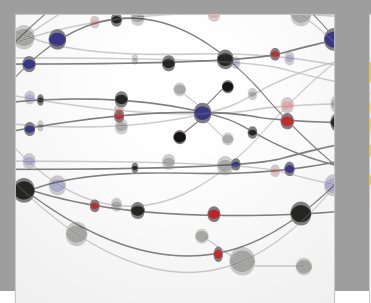

The Scientific World Journal

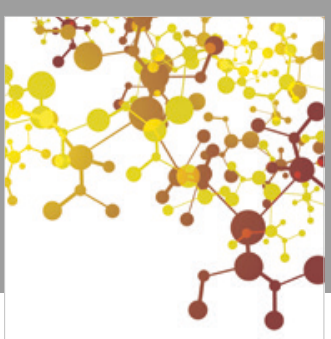

Journal of

Applied Chemistry
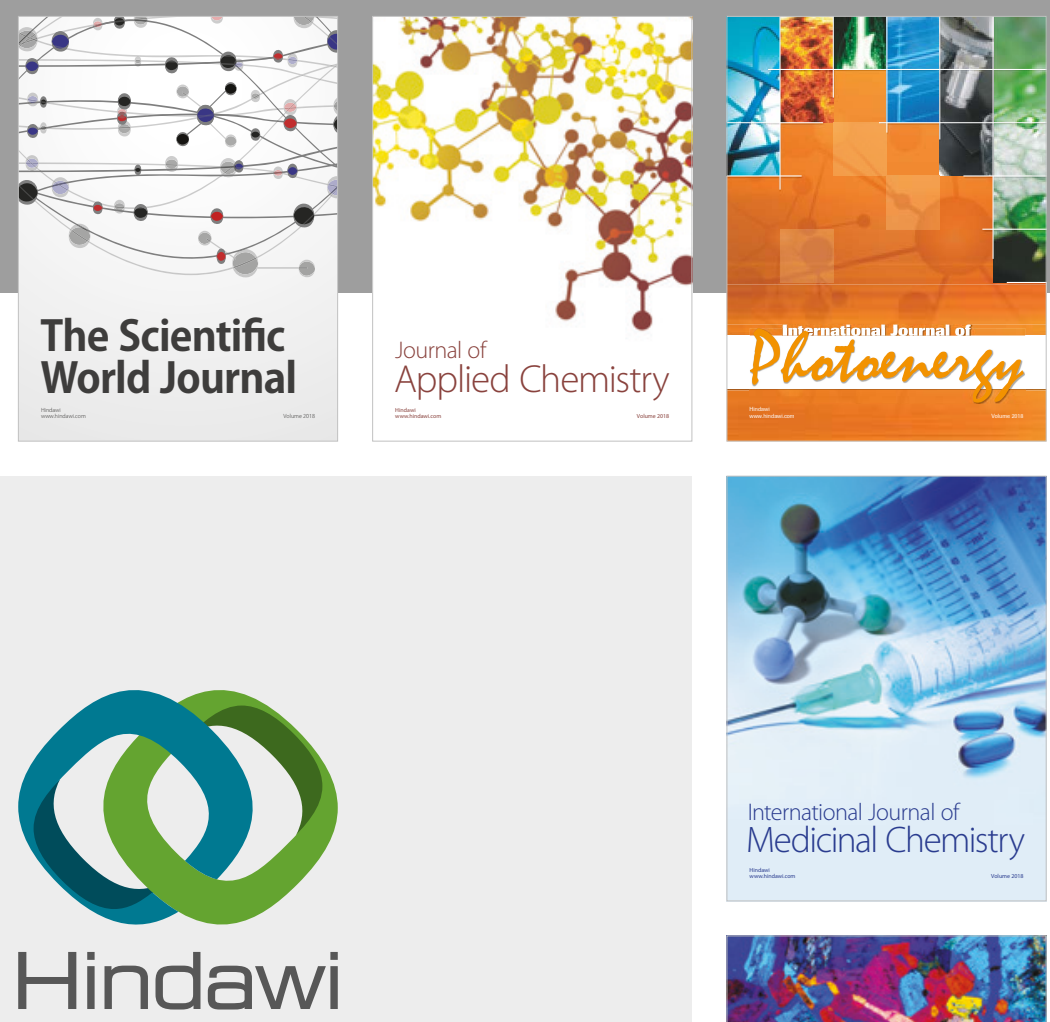

Submit your manuscripts at

www.hindawi.com
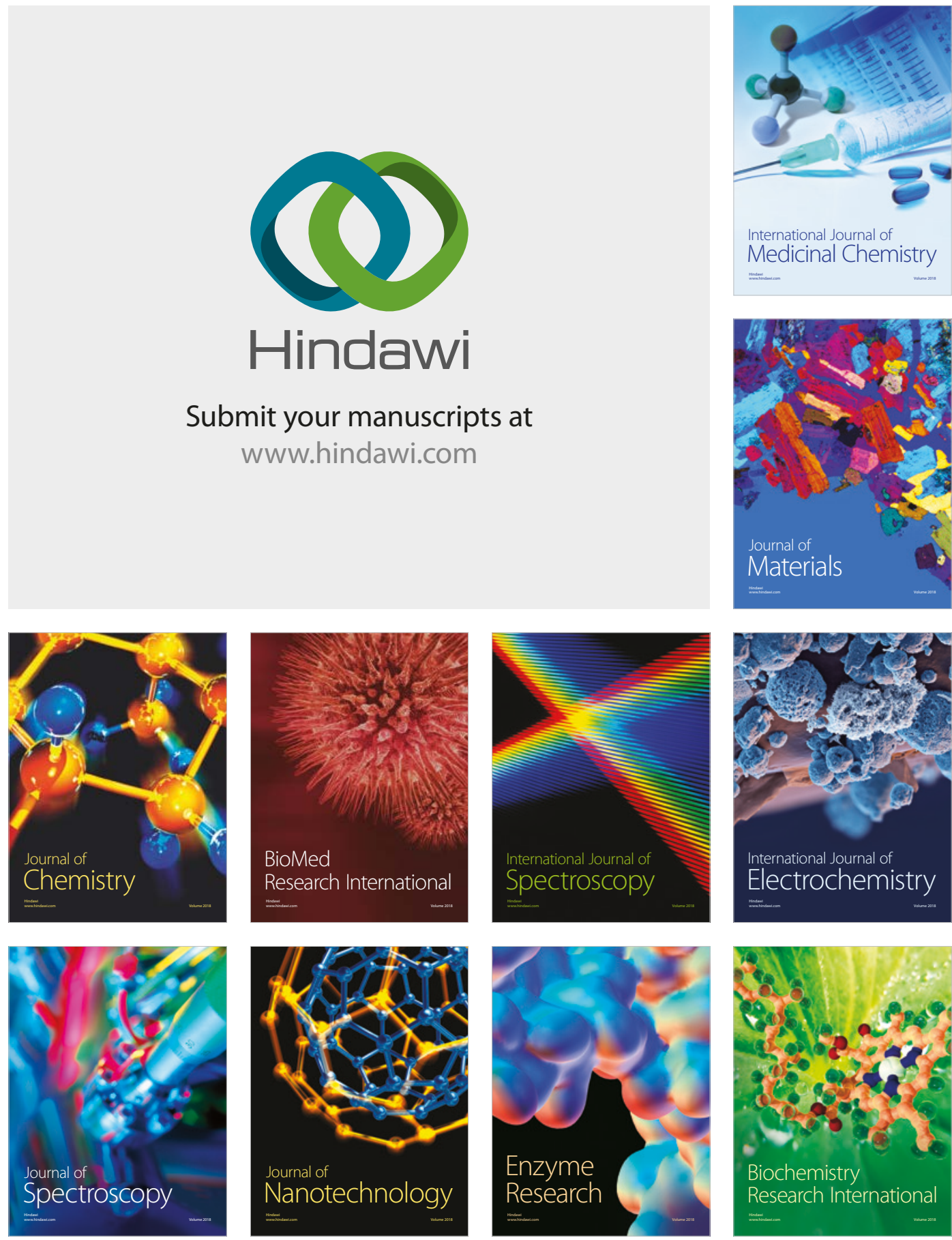
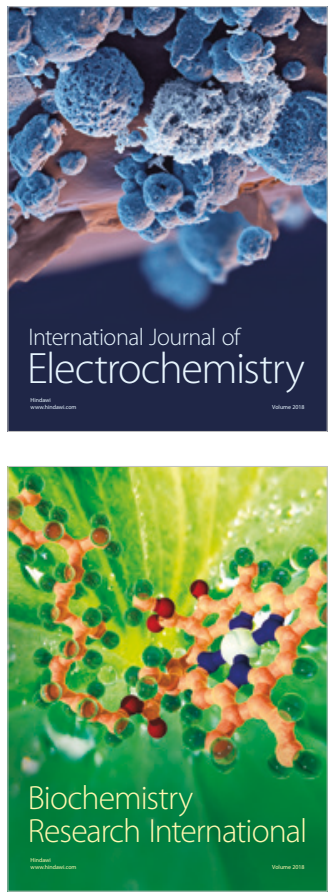